\title{
Para un repertorio de las Rimas de Cristóbal de Mesa
}

\author{
Giovanni CARAVAGGI \\ Università degli Studi di Pavia
}

\section{RESUMEN}

Falta todavía una edición crítica de las Rimas de Cristóbal de Mesa, que ni siquiera han sido estudiadas detenidamente hasta ahora. El autor mismo no aseguró una ordenación autónoma de sus líricas, publicándolas, con entregas sucesivas, a la zaga de otras obras que quizás considerba más importantes (poemas heroicos, poemas religiosos, traducciones de clásicos). A la valoración de su creación poética se intenta contribuir con esta humilde tarea de un repertorio pormenorizado.

Palabras clave: Cristóbal de Mesa, poesía del Siglo de Oro.

\begin{abstract}
We still need a critical edition and thorough analysis of Cristóbal de Mesa's Rimas. What is more, the author never organized in autonomous form his poems, which were published in different times as an appendix of works he considered more important, such as epic, religious poetry, translations from the classics. The present detailed inventory attempts to offer a contribution to the critcal knowledge of the lyric poet's work.
\end{abstract}

Key words: Cristóbal de Mesa, Siglo de Oro poetry.

\section{Nota previa}

Un estudio sistemático de las Rimas de Cristóbal de Mesa no se ha realizado todavía; sigue faltando, desde luego, una edición crítica de sus obras, como se ha indicado en otras ocasiones ${ }^{1}$. El autor, por su parte, no favoreció una transmisión orgánica de su producción poética; en particular, sus colecciones líricas no recibieron nunca una ordenación autónoma, quedando insertadas en obras no muy homogéneas, respectivamente $V L, P E$ y $E G$, donde se mezclan géneros literarios diferentes; la más unitaria es quizás $V L$, donde una breve serie de poemas religiosos precede a un primer conjunto de "diversas Rimas"; mientras en $P E$ se juntan un poema heroico, de extensión bastante limitada, y una segunda entrega de Rimas; y en $E G$ se suceden, de manera aún menos orgánica, las traducciones de textos

${ }^{1}$ Cfr. G.Caravaggi 2007 y 2010. 
virgilianos, una nueva colección de Rimas y una tragedia. Ni siquiera se ha compilado hasta ahora un repertorio completo de los poemas de este autor. En el t. XIV de su B. L. H., por ejemplo, J. Simón Díaz presenta una descripción pormenorizada tan sólo de $P E$ (n.5597, pp. 666-668), y, concretamente, no se sabe mucho de lo que contienen $V L$ y $E G$. La única edición de nuestros días ${ }^{2}$ se limita a un florilegio antológico, con acotaciones exiguas; pero esa compleja producción lírica exige sin duda una mayor consideración.

El primer conjunto se publicó en 1607, bajo el título Valle de lágrimas y diversas Rimas; el Valle de lágrimas comprende seis breves poemas de carácter religioso, relacionados entre sí por el motivo común del llanto: Llanto del Real Profeta David, Llanto de Nuestra Señora, Llanto de San Pedro, Llanto de la Madalena, Llanto de San Francisco, Llanto de San Agustín; pertenecen a un subgénero poético que se puede considerar típico de la sensibilidad post-tridentina, y tienen una relación estrecha con análogas composiciones de dos influyentes amigos italianos de Cristóbal de Mesa, Le Lagrime di San Pietro de Luigi Tansillo, Le lagrime di Maria Vergine y Le lagrime di Gesù Cristo de Torquato Tasso (pero se podrían mencionar otras obritas bastante parecidas que circulaban en Italia en el periodo de la estancia de Mesa, como Le lagrime della Maddalena de Erasmo Valvassone y las Rime spirituali de Angelo Grillo). En los fols. 55r - 56r se incluye la dedicatoria de una primera entrega de rimas: A don Gómez Suárez de Figueroa y Córdoba, Marqués de Villalba; en los fs. 95r - 96v aparece la dedicatoria de otro grupo de rimas $A$ don Pedro Fernández de Córdoba y Figueroa, Marqués de Priego; en el f. 163v el colofón: En Madrid. por Juan de la Cuesta. Año MDCVI. Concretamente, en las Rimas incluidas en $V L$ se mezclan, sin orden plausible, poemas amorosos, de elegante manierismo herreriano, y poemas de circunstancia, de importante valor evocatorio; muchos de ellos se compusieron en Italia o recuerdan experiencias del poeta en Roma, Nápoles y Pavía, celebrando sus encuentros literarias más importantes. A pesar de la fecha de edición, se concentra aquí una producción que parece remontarse a las últimas décadas del siglo XVI.

En el mismo año se publican en Madrid, por el mismo editor, dos obras significativas de Cristóbal de Mesa, $R E$ y $V L$; comparando los datos editoriales y los preliminares de ambas se notan no pocas coincidencias, y casi parece que en un primer momento el autor quisiese publicarlas en un único libro. Concretamente en la Censura del Maestro Fray Athanasio de Lobera, con fecha 20 de octubre de 1604, repetida en ambas obras, se menciona un único libro: "La Restauración de España con otras Rimas, compuesta por Christóbal de Mesa, he visto por mandado de V. Alteza, y no hallo cosa que impida el poder dar licencia para que se imprima..." Pero los dos títulos se han distiguido ya en los respectivos Privilegios (ambos de 10 años en favor de Esteban de Bugia, mercader de libros, ambos con

${ }^{2}$ Cfr. C. de Mesa 1991. 
fecha del 16 de noviembre de 1604), como también en los otros preliminares, la Fee de las erratas, prácticamente inconsistente, con fecha del 10 de febrero de 1606 en ambas obras, y la Tasa, con idéntica fecha del 13 de octubre de 1606, pero especificando 23 pliegos y medio, por un valor de 71 maravedís, con respecto a $R E$, y 21 pliegos y medio, por un valor de 64 maravedís, con respecto a $V L$.

En $P E$ se reunen, efectivamente, dos obras diferentes, como se ha señalado, el poema sobre Santiago y la segunda entrega de las Rimas, pero cada una con su propia portada y fecha de edición (Madrid 1612 y Madrid 1611, respectivamente). La portada inicial se refiere tan sólo a la primera obra: El Patrón de España de Christóbal de Mesa. Al Rey Don Felipe Tercero nuestro señor. Año 1612. Con Privilegio. En Madrid. Por Alonso Martín. A costa de Miguel de Siles librero; en el fol. 94r aparece otra portada: Rimas de Cristóbal de Mesa. A don Alonso de Zúñiga y Sotomayor, Duque de Bejar... [etc.]. En Madrid. Por Alonso Martin. Año 1611. Solamente El Patrón de España lleva preliminares; la Suma de Privilegio, con fecha en Madrid, a 17 de febrero de 1611, se refiere a un único título: "Este libro, intitulado El Patrón de España..."; en las Erratas, al cuidado del Licenciado Murcia de la Llana (y con fecha del 16 de diciembre de 1611) se menciona una sola obra ("Vi este libro intitulado El Patrón de España, compuesto por el licenciado Christóbal de Mesa..."); sin embargo se corrigen también unos versos de las Rimas; mientras que en la Tasa, con fecha del 28 de diciembre de 1611, se indica el contenido de manera más completa: "Yo Antonio de Olmedo, escribano de la Cámara del Rey nuestro señor, de los que residen en su Consejo, doy fe, que habiéndose visto por los señores dél un libro, que compuso Christóbal de Mesa, intitulado de Santiago, en verso heroyco, y otras rimas, en estilo lírico, que con su licencia fue impreso, le tasaron a tres maravedís el pliego, el cual tiene ventinueve pliegos, que al dicho precio suma y monta ochenta y siete maravedís, sin los principios..." La Aprobación y la Censura, ambas a cargo del Maestro Fray Hortensio, no ofrecen elementos interesantes. Desde luego, el autor no menciona las Rimas añadidas a su último poema heroico ni en la dedicatoria $\mathrm{Al}$ rey don Felipe Tercero N. S. ni tampoco en el prólogo A los lectores.

En lo que se refiere a $E G$ (Madrid, 1618), se verifica algo parecido, porque la tercera entrega de las Rimas (ff. 109v - 159v) se inserta entre la traducción de las Éclogas y Geórgicas (ff. 1r - 31r y ff. 31v - 109r) y la tragedia El Pompeyo (ff. $160 \mathrm{r}-191 \mathrm{v}$ ), sin ninguna portadilla intermedia u otro tipo de separación, pasándose sin solución de continuidad de la última página de las Geórgicas (f. 109r) a la traducción del Beatus ille de Horacio (Dichoso el que alexado..., f.109v), con la que empieza la nueva colección de líricas.

Por lo tanto parece evidente que Cristóbal de Mesa no quiso construir un cancionero homogéneo, sino que publicó sus Rimas más o menos ocasionalmente, a la zaga de otras obras a las que probablemente esperaba encomendar su fama poética, es decir los poemas heroicos y religiosos y las traducciones de los clásicos. Éstas ocupan una gran parte de la última actividad literaria del poeta; sus versiones 
de la Eneida (Madrid, 1615), así como las de las Éclogas y Geórgicas, ya mencionadas, se acompañaron a las versiones (o a veces, elaboraciones) de algunas Odas de Horacio, que se concentran sobre todo en la tercera entrega de las Rimas.

En un estudio sobre la creación poética de Cristóbal de Mesa será oportuno considerar, además, el conjunto de poemas laudatorios (casi todos sonetos) ofrecidos al autor por varios amigos y colocados al comienzo o al final de sus obras, porque en su compleja variedad atestiguan, entre otras cosas, la envergadura de las relaciones literarias entabladas por el poeta.

$\mathrm{Y}$ a la valoración de su personalidad podría contribuir también esta humilde tarea de un repertorio más pormenorizado.

\section{Abreviaciones}

NT - $\quad$ Las Navas de Tolosa

RE - $\quad$ La Restauración de España

$V L$ - $\quad$ Valle de lágrimas y diversas rimas

PE - $\quad$ El Patrón de España

EN - $\quad$ La Eneida de Virgilio

EG - Las Éclogas y Geórgicas de Virgilio, y Rimas, y el Pompeyo tragedia

N.B.

- Para la numeración de los preliminares se utiliza extensivamente el símbolo $\uparrow$, aunque el calderón, como es notorio, no figure en todas las hojas de esta sección.

- Oy..., Qual..., Quando..., Quanto..., etc. > Hoy..., Cual.., Cuando..., Cuanto..., etc.

\section{LAS NAVAS DE TOLOSA}

Las Navas de Tolosa. Poema heroico de Cristóbal de Mesa. Al Príncipe don Felipe N. S. [escudo] Con Privilegio. En Madrid, por la viuda de P. Madrigal. A costa de Esteban Bogia [sic]. Año 1594.

$8 \mathrm{hs}+324$ fols $+2 \mathrm{hs}$.

Tasa (Gonzalo de la Vega). Madrid, 28 de junio de 1594, 92 2r.

Erratas (Juan Vázquez del Mármol). Madrid, 14 de junio de 1594, $92 \mathrm{v}$.

Privilegio (Por mandado del Rey N. S., Don Luis de Salazar). San Lorenzo, 28 de agosto de 1593, ๆ 3r-4r.

Aprobación (Don Alonso de Ercilla y Zúñiga), ๆ 4v.

[Dedicatoria] Al Príncipe n[uest]ro Señor [«Con razón se dedica a V[uestra] Alt[eza] este poema... »] $₫ 5$ r. 
Cristóbal de Mesa a Torcuato Taso a Mantua donde fue desde Roma. Soneto [«Là dove il grande in lira, in cetra, in tromba...»] \ $5 \mathrm{v}$.

Torcuato Taso a Cristóbal de Mesa a Roma. Soneto [" "Quei che con sommo studio il mondo ammira...»] \ 6r.

De Geronimo Gagliardi. Soneto [«Vivo essempio di gloria, honor di quelli...»] ๆ $6 \mathrm{v}$.

Argumento del Canto Primero [«Dios por un ángel manda al rey de España.... »] f. $1 \mathrm{r}$.

Canto Primero [«Las armas y el católico rey canto.... »] f. 1r.

De Pedro Ramírez de Guzmán. Soneto [«Altivo el Mincio, y con razón contento...»] f. 324v.

De Baltasar de Escobar. Soneto [«De la ciudad que guarda el Mausoleo...»] f. $325 \mathrm{r}$.

De Miguel López de Aguirre. Soneto [«A la orilla del úmedo elemento...»] f. 325v.

Del Licenciado Diego Vélez de Dueñas. Soneto [«Fama, si sueles con sonora trompa...»] f. 326r.

De Francisco Cascales. Soneto [«A los filos de aquella ardiente espada...»] f. $326 \mathrm{v}$.

[Colofón]. En Madrid, por la viuda de Pedro Madrigal, 1594.

\section{LA RESTAURACIÓN DE ESPAÑA}

La Restauración de España de Cristóbal de Mesa. Al Rey don Felipe Tercero nuestro Señor. Año [escudo] 1607. Con Privilegio. En Madrid. En casa de Juan de la Cuesta. A costa de Esteban Bugia mercader de libros. 8 hs. +180 fols.

Tasa (Alonso de Vallejo) Madrid 13 de octubre de 1606, \2r.

Fe de las erratas (Licenciado Francisco Murcia de la Llana) Madrid, 10 de febrero de 1606. 92 2r.

Suma del Privilegio. Valladolid, 16 de noviembre de 1604, $92 \mathrm{v}$.

Censura (Maestro Fray Athanasio de Lobera) Valladolid, 20 de octubre de 1604, 9 2v.

[Dedicatoria.] Al Rey don Felipe Tercero, nuestro Señor [«En el libro de Las Navas de Tolosa que dediqué a V.M. ...»] \ 3r.

A los lectores [«Si bien en el Prólogo de Las Navas de Tolosa traté de la dificultad...»] \ 3v-5r.

Al Rey nuestro Señor, del Doctor Agustín de Tejada y Páez, Canción [«Tal como escuchas, o Alexandro nuevo...»] \ 5v.

Alabanza a Cristóbal de Mesa. Don Francisco de Quevedo. Soneto [«Hoy de los hondos senos del olvido...»] $₫ 7 \mathrm{r}$.

Del Doctor Fr. Miguel Cejudo, del hábito de Calatrava. Soneto: [«Venció Pelayo, y para gloria nuestra... »] ๆ $7 \mathrm{r}-\mathrm{v}$. 
De Luis Barahona de Soto. Soneto [«En dos poemas de dos Reyes santos...»] \ 7v. De don Luis Manuel. Soneto [«El sacro Cisne que entre el Moncio [sic, por Mincio] y Pado...»] đ| 8r.

Respuesta [«Si navegáis de amor por el estrecho...»] ๆ 8r-v.

Libro Primero de la Restauración de España ["Yo que canté las armas y vitoria..."] f. $1 \mathrm{r}$.

Del Padre Fray Cristóbal de Zafra, Rector del Colegio de San Lorenzo el Real, Primo del autor. Soneto [«Doblada deve a vos palma y corona...»] f.179v.

Del Licenciado don Luis Xara, Gobernador de Zafra, primo del autor. Soneto [«Si de dos griegos canta el griego Homero...»] f. 180r.

De don Hernando de Guzmán. Soneto [«A los grandes espíritus de Italia...»] Laus Deo f. 180 v.

\section{VALLE DE LÁGRIMAS Y DIVERSAS RIMAS}

Valle de lágrimas y diversas Rimas de Cristóbal de Mesa. A don Lorenzo Suárez de Figueroa y Córdoba, Duque de Feria, Marqués de Villalba, Señor de las casas de Salvatierra, Virrey y Capitán General en el Reyno de Sicilia, etc. [escudo]. Con Privilegio. En Madrid. En casa de Juan de la Cuesta. Año 1607. A costa de Esteban Bugia Mercader de libros.

8 hs. +163 fols.

Tasa (Alonso de Vallejo) Madrid, 13 de octubre de 1606, ๆ 2r

$\mathrm{Fe}$ de las erratas (Licenciado Francisco Murcia de la Llana) Madrid, 10 de febrero de 1606, \2r

Suma del Privilegio. Valladolid, 16 de noviembre de 1604, $₫ 2 \mathrm{v}$

Censura (Maestro Fray Athanasio de Lobera) Valladolid, 20 de octubre de 1604, 9 $2 \mathrm{v}$

Ded[icatoria] a don Lorenzo Suárez de Figueroa y Córdoba, Duque de Feria, Marqués de Villalba, Señor de las casas de Salvatierra, Virrey y Capitán General en el Reyno de Sicilia, [«Aunque la obligación que tengo...»], \| 3r-6v.

A don Lorenzo Suárez de Figueroa y Córdoba, Duque de Feria. Soneto [«La Antigüedad llama a Platón divino...»] \ 7r.

Otro soneto al Duque de Feria [«Vuelve a su patria, o mar sagrado a uno...»] \ 7r$7 \mathrm{v}$.

De Camilo Peregrino. Soneto [«Ove fia che non giunga e che non versi...»] $\uparrow 7 \mathrm{v}-$ $8 \mathrm{r}$.

De Felice Milencio. Soneto [«Sia pur ceraunio scoglio o selce alpina...»] $\mid$ | 8r.

De Giulio Caria. Soneto [«Valle, che le tue verdi e ricche sponde...»] \ 8r-v.

Llanto del Real Profeta David [«Las lágrimas del Rey profeta canto...»] ff. 1r-10r.

Llanto de Nuestra Señora [«Las lágrimas diré de aquellos ojos...»] ff. 10v-19v.

Llanto de San Pedro [«Del que del gallo al matutino canto...»] ff. 20r-28v. 
Llanto de la Magdalena [«Bien puedes tú, llorosa Magdalena...»] ff. 29r-38v. Llanto de San Francisco [«Lágrimas, llagas, penitencia canto...»] ff. 39r-46r. Llanto de San Agustín [«Del africano gran doctor latino...»] ff. 46v-54v.

Ded[icatoria] a Don Gómez Suárez de Figueroa y Córdoba, Marqués de Villalba [«Opinión es de los Maestros de la poesía...»] ff. 55r-56r.

[Dedicatoria] A Don Gómez Suárez de Figueroa y Córdoba, Marqués de Villalba. Soneto [«Único sucesor del grande Estado...»] f. 56v.

Rimas de Cristóbal de Mesa f. 57r.

$V L$ 1. Soneto [«Espíritus gentiles que a mi canto...»] f. 57r.

$V L$ 2. Soneto [«Amor, es un alegre pensamiento...»] ff. 57r-v.

$V L$ 3. Soneto [«Amor hizo en mi alma una ancha puerta...»] ff. $57 \mathrm{v}-58 \mathrm{r}$.

$V L$ 4. Soneto [«De un pensamento en otro pensamento...»] f. 58r.

$V L$ 5. Soneto [«Bella, gentil, preciosa Margarita...»] ff. 58r-v.

$V L$ 6. Soneto. [« Si la soberbia magestad latina...»] ff. 58v-59r.

$V L$ 7. Soneto [«Aunque lo que al valor vuestro se debe...»] f. 59r.

$V L$ 8. Soneto [« Estampa singular de hermosura...»] ff. 59r-v.

$V L$ 9. Soneto [«Soñé, Señora, el más alegre sueño...»] ff. 59v-60r.

$V L$ 10. Soneto [«Finge la antigüedad al grande Atlante...»] f. 60r.

$V L$ 11. Soneto [«Mientras en carta, en lienzo, en varia tinta...»] ff. 60r-v.

$V L$ 12. Soneto [«Arde en mi pecho un amoroso fuego...»] ff. 60v-61r.

$V L$ 13. Soneto [«Si Tántalo desea, deseo y siento...»] f. 61r.

$V L$ 14. Soneto [«Viénese al suelo la alta antigua Troia...»] ff. 61r-v.

$V L$ 15. Soneto [«Cuánto más vuelen los ligeros cielos...»] f. 61v.

$V L$ 16. Soneto [«Junto es cruel y plácida Sirena...»] f. 62r.

$V L$ 17. Soneto [«iSi amor me hace osado, por qué temo...?»] ff. 62r-v.

$V L 18$ Soneto [«Tuve un tiempo y tendré siempre esperanza...»] ff. $62 \mathrm{v}-63 \mathrm{r}$.

$V L 19$ Soneto. [«Tiéneme vuelto amor un breve mundo...»] f. 63r.

$V L$ 20. Soneto [«¿Cuándo ha de ser aquel dichoso día...?»] ff. 63r-v.

$V L$ 21. Soneto [«Por la alta sombra de la noche oscura...»] ff. $63 \mathrm{v}-64 \mathrm{r}$.

$V L 22$ Soneto [«Betis, que caudalosa, ancha corriente...»] f. 64r.

$V L$ 23. Soneto [«O Betis caudaloso, Rey de ríos...»] ff. 64r-v.

$V L$ 24. Soneto [«Del presente al antiguo Siglo de Oro...»] ff. 64v-65r.

$V L$ 25. Soneto [«Si descrivo el sujeto soberano...»] f. $65 \mathrm{r}$.

$V L$ 26. Soneto [«Cuanto procuro más celebrar una...»] ff. 65r-v.

$V L$ 27. Soneto [«De amor en la agradable compañia...»] ff. $65 \mathrm{v}-66 \mathrm{r}$.

$V L$ 28. Soneto [«Flaco ingenio, mal verso, estilo rudo...»] f. 66r.

$V L$ 29. Soneto [«Los dos Soles, las dos lámparas claras...»] ff. 66r-v.

$V L$ 30. Soneto [«Una Diosa nació con Febo en Delo...»] ff. 66v-67r.

$V L$ 31. Soneto [«En tanto que el color de nieve y grana...»] f. $67 \mathrm{r}$.

$V L$ 32. Soneto [«Vivo en cuidado, en pena, en prisión dura...»] ff. $67 \mathrm{r}-\mathrm{v}$.

$V L$ 33. Soneto [«Cuando ya tus cabellos y tus ojos...»] ff. $67 \mathrm{v}-68 \mathrm{r}$.

$V L$ 34. Soneto [«Burlóme amor con esperanza incierta...»] f. $68 \mathrm{r}$. 
$V L$ 35. Soneto [«Nuevos colores busque y nueva tinta...»] ff. $68 \mathrm{r}-\mathrm{v}$.

$V L$ 36. Soneto [«Silvia, oyó el cielo, oyó mi ruego el cielo...»] ff. $68 \mathrm{v}-69 \mathrm{r}$.

$V L$ 37. Soneto [«En la tormenta, a quien amor me entrega...»] f. 69r.

$V L$ 38. Soneto [Cuando la edad, de bienes robadora...»] ff. 69r-v.

$V L$ 39. Soneto [«Mientras debajo de tu Imperio injusto...»] ff. $69 \mathrm{v}-70 \mathrm{r}$.

$V L$ 40. Soneto [«Gusta mi dama que la sirva y ame...»] f. 70r.

$V L$ 41. Soneto [«Si levanto en tu honor alto teatro...»] ff. 70r-70v.

$V L$ 42. Soneto [«¿Quién me dará favor para que cante...?»] ff. 70v-71r.

$V L$ 43. Soneto [«Como cuando el timón pierde el Piloto...»] f. 71r.

$V L$ 44. Soneto [«El tempestuoso invierno escuro y cano...»] ff. 71r-v.

$V L$ 45. Soneto [«El tiempo en varios pensamientos gasto...»] ff. $71 \mathrm{v}-72 \mathrm{r}$.

$V L$ 46. Soneto. [«Doma un niño gigante un lince ciego...»] f. 72r.

$V L$ 47. Soneto [«Si el gran valor, si el rostro peregrino...»] ff. 72r-v.

$V L$ 48. Soneto [«El fin porque se mueve el sabio y fuerte...»] ff. $72 \mathrm{v}-73 \mathrm{r}$.

$V L$ 49. Soneto [«Todo al fin tiene fin, todo alto Imperio...»] f. $73 \mathrm{r}$.

$V L$ 50. Soneto [ «A beber apostaron con dos nueces...»] ff. 73r-v.

$V L$ 51. Soneto [ «Si encima de las alas de alto verso...»] ff. $73 \mathrm{v}-74 \mathrm{r}$.

$V L$ 52. Soneto [«Adiós, amiga solitaria selva...»] f. 74r.

$V L$ 53. Soneto [«Si en el espacio de la edad incierta...»] ff. 74r-v.

$V L$ 54. Soneto [«Miro el turbado mar desde la tierra...»] ff. 74v-75r.

$V L$ 55. Soneto [«Tú, plateada vega, húmeda Luna...»] f. 75r.

$V L$ 56. Soneto [«Si os tengo amor por natural instinto...»] ff. 75r-v.

$V L$ 57. Soneto [«Si estilo que no fuere soberano...»] ff. $75 \mathrm{v}-76 \mathrm{r}$.

$V L$ 58. Soneto [«Antes que de la vida el tiempo breve...»] f. 76r.

VL 59. Fábula de Narciso traducida de Ovidio. [«Bellísima Isabel, cuya hermosura...»] ff. $76 \mathrm{v}-83 \mathrm{v}$.

VL 60. Égloga. Melampo. Camilo. [«El tierno canto, y plácidas querellas...»] ff. $84 \mathrm{r}-92 \mathrm{v}$.

$V L$ 61. Sestina [«La vuelta ha dado el cielo al décimo año...»] ff. 93r-v.

$V L$ 62. Sestina [«Voy por aquesta solitaria selva...»] ff. 93v-94v.

Ded[icatoria] a Don Pedro Fernández de Córdoba y Figueroa, Marqués de Priego y Montalbán, Señor de la casa de Aguilar y Castroelrio [«Si con justo título es condenada la ingratitud...»] ff. 95r-96v.

$V L$ 63. Soneto [«Magnánimo Marqués, nieto y sobrino...»] f. 97r.

$V L$ 64. Soneto [«Yo con silencio voy por vida quieta...»] ff. 97r-v.

$V L$ 65. Soneto [«Lejos voy del profundo vulgo incierto...»] ff. 97v-98r.

$V L$ 66. Soneto [«Tiempo fue ya que amor con burla y juego...»] f. $98 \mathrm{r}$.

$V L$ 67. Soneto [《Esta desierta y solitaria tierra...»] ff. $98 \mathrm{r}-\mathrm{v}$.

$V L$ 68. Soneto [«Todo el tiempo cruel trueca y revuelve...»] ff. 98v-99r.

$V L$ 69. Soneto [«En medio del discurso de mi vida...»] f. 99r.

$V L$ 70. Soneto [«Salvo en la tierra, al cielo, o mar sagrado...»] ff. 99r-v.

$V L$ 71. Soneto [«Si al fin de largo tiempo, al cielo plugo...»] ff. $99 \mathrm{v}-100 \mathrm{r}$. 
$V L$ 72. Soneto [«Hojeando el cuaderno de mi vida...»] f. 100r.

$V L$ 73. Soneto [《En cada mano tiene la fortuna...»] ff. 100r-v.

$V L$ 74. Soneto [«Huyendo de los ojos de las gentes...»] ff. 100v-101r.

$V L$ 75. Soneto [«Viste el campo la alegre Primavera...»] f. 101r.

$V L$ 76. Soneto [«Pasan apriesa los ligeros días...»] ff. 101r-v.

$V L$ 77. Soneto [«Siempre seguí la vida solitaria...»] ff. 101v-102r.

$V L$ 78. Soneto [«Ya me fue favorable la fortuna...»] f. 102r.

$V L$ 79. Soneto [«Cual el sutil Astrólogo que solo...»] ff. 102r-v.

VL 80. Soneto [《El que con admirable magisterio...»] ff. $102 \mathrm{v}-103 \mathrm{r}$.

$V L$ 81. Soneto [«Ande ufano el privado poderoso...»] f. 103r.

$V L$ 82. Soneto [«Teatro, Capitolio, Coliseo»] ff. 103r-v.

$V L$ 83. Soneto [«Si las ínclitas obras peregrinas...»] ff. $103 \mathrm{v}-104 \mathrm{r}$.

VL 84. A Gofredo de Bullón. Soneto [«Glorioso Capitán, digno del canto...»] f. $104 \mathrm{r}$.

$V L$ 85. Al Marqués de Tarifa. Soneto [«Si celebró la edad antigua tanto...»] f. 104v.

$V L$ 86. Al mismo Marqués. Soneto [«Al Tajo altivo que con urna de oro...»] ff. $104 \mathrm{v}-105 \mathrm{r}$.

VL 87. Al mismo Marqués. Soneto [«La que me concedéis laurea corona...»] ff. $105 \mathrm{r}-\mathrm{v}$.

VL 88. Al Conde de Niebla, dándole las galeras. Soneto [«Ya, claro Conde, el grande padre Océano...»] f. 105v.

VL 89. Al mismo Conde. Soneto [«Ya las reales, ínclitas galeras...»] f. 106r.

VL 90. A la Duquesa de Medina Sidonia, con su nombre en las primeras letras. Soneto [«Darte alabanzas, ínclita Princesa...»] ff. 106r-v.

VL 91. A la Duquesa de Medina de Rioseco, con su nombre en las primeras letras. Soneto [«Doña de gran valor, alta corona...»] ff. 106v-107r.

VL 92. A la Duquesa de Pastrana. Soneto [«Sois del alto poder grande misterio...»] ff. $107 \mathrm{r}-\mathrm{v}$.

VL 93. Al Duque Julián Cesarino en Roma. Soneto [«Las águilas que el pueblo alto romano...»] f. $107 \mathrm{v}$.

VL 94. Al Príncipe de Saboya. Soneto [«Aquel Norte de Italia, única joya...»] f. 108 r.

$V L$ 95. Al de Saboya. Soneto [«Cuarto Felipe, nieto al gran Segundo...»] ff. 108r-v. VL 96. A Don Luis Vanegas, Caballero del hábito de Santiago, yendo con el Duque de Feria de Roma a Francia. Soneto [«Alma noble, si en voz, si en son, si en rima...»] ff. $108 \mathrm{v}-109 \mathrm{r}$.

VL 97. A Don Diego de Vargas, en respuesta de unos tercetos. Soneto [«Tu cítara gentil que dulce admira...»] ff. 109r-v.

VL 98. A Saboya. Soneto [«Hoy el cuarto Filipo Filiberto...»] f. 109v.

VL 99. A Don Diego de Córdoba, hijo del Señor de Guadalcazar. Soneto [«Gran Don Diego de Córdoba, a ti solo...»] f. 110r. 
VL 100. Al Condestable. Soneto [«Nuevo Agusto español, nuevo Mecenas...»] ff. $110 \mathrm{r}-\mathrm{v}$.

VL 101. A Don Mateo de Leca, Arcediano de Carmona, Canónigo de Sevilla. Soneto [«Tal valor, tal caudal, o gran Mateo...»] ff. 110v-111r.

VL 102. A Luis Barahona de Soto. Soneto [«Soto, aquí donde el gran Betis deciende...»] f. 111r.

VL 103. Al retrato del Doctor Herrera, predicador famoso. Soneto [ «Si bien ya con la voz viva no suenas...»] f. 111v.

VL 104. A la Antoniana del padre Maestro Fray Hernando Suárez Provincial. Soneto [《La vida solitaria del desierto...»] ff. 111v-112r.

VL 105. Al retrato de Gerónimo de Carranza, Caballero del hábito de Christo. Soneto [«Tú, gran Carranza, que andaluz Atlante...»] ff. 112r-v.

$V L$ 106. De Baltasar de Escobar desde Roma a Nápoles. Soneto [«De la ciudad que guarda el Mauseolo...»] ff. 112v-113r.

VL 107. Respuesta en loor de su Poema del Ermenegildo. Soneto [«Católico gran Príncipe, que al yugo...»] f. 113r.

VL 108. A Doña Christobalina de Córdoba, Poeta de Antequera. Soneto [«Vos del nombre del que es Christo Atlante...»] f. 113v.

VL 109. De Luis Barahona de Soto, a la Restauración de España. Soneto [«En dos poemas de dos Reyes santos...»] ff. $113 \mathrm{v}-114 \mathrm{r}$.

VL 110. A Torquato Tasso a Mantua desde Roma. Soneto [«Là dove il grande in lira, in cetra, in tromba...»] ff. 114r-v.

$V L$ 111. Respuesta del Taso a Roma. Soneto [«Quei che con sommo studio il mondo ammira...»] f. 114v.

VL 112. A Gerónimo Gagliardi, Napolitano. Soneto [«Bel foco, fiama mole, e dulce lume...»] f. $115 \mathrm{r}$.

VL. 113. Respuesta del Gagliardi. Soneto [«Vivo esempio di gloria, honor di quelli...»] ff. 115r-v.

$V L$ 114. Soneto [«No se debe dolor, luto ni llanto...»] ff. $115 \mathrm{v}-116 \mathrm{r}$.

$V L$ 115. Soneto [«Tú, de la vida en el espacio incierto...»] f. 116r.

VL 116. Al Cardenal Alejandro Farnesio en Roma. Soneto [«Nunca la antigua ni moderna Roma...»] ff. 116r-v.

$V L$ 117. Al mismo Cardenal. Soneto [ $[\mathrm{Si}$ al gran Francisco lloras como a muerto...»] ff. 116v-117r.

VL 118. Al mismo Cardenal. Soneto [«Púrpura roja y cárdena azucena...»] f. 117r.

VL 119. Al mismo Cardenal. Soneto [«Tus siete montes, Roma, en varias rimas...»] f. $117 \mathrm{v}$.

VL 120. Al Rey Don Filipe Segundo. Soneto [«Fue Filipe sol nuevo en Ocidente...»] ff. $117 \mathrm{v}-118 \mathrm{r}$.

VL 121. Al mismo Rey. Soneto [«Al gran Rey, gran Filipe, gran Monarca...»] ff. $118 \mathrm{r}-\mathrm{v}$.

VL 122. Al mismo Rey. Soneto [«Las obras que a la fama y la memoria...»] f. 118v. 
VL 123. Al Conde de Cabra. Soneto [«Luz del blasón de Córdoba y Cardona...»] f. $119 \mathrm{r}$.

VL 124. Al mismo Conde. Soneto [«De Capitán dio a César nombre el mundo...»] ff. 119r-v.

VL 125. A Don Juan de Arguijo, veinticuatro de Sevilla. Soneto [«La flor del nombre de Ayax y Jacinto...»] ff. 119v-120r.

VL 126. Al nacimiento del Príncipe nuestro Señor, que fue en Viernes Santo. Soneto [«Al tiempo que la fértil Primavera...»] ff. 120r-v.

$V L$ 127. Soneto [«Tú, Fidelio, con verso peregrino...»] f. 120v.

VL 128. A San Lorenzo. Soneto [«Diácono Español que al mundo ciego...»] f. 121 r.

$V L$ 129. Soneto [«Cuando en la eternidad del tiempo pienso...»] ff. $121 \mathrm{r}-\mathrm{v}$.

$V L$ 130. Canción [«España mía, siento y lloro en vano...»] ff. 121v-124r.

$V L$ 131. Vida solitaria [«Sólo aquel venturoso...»] ff. 124v-132r.

$V L$ 132. Super Flumina Babylonis. Psalm 136 [«Junto a los claros ríos...»] ff. $132 \mathrm{v}-133 \mathrm{v}$.

VL 133. Beatus vir qui non abiit. Psalm 1 [«O bienaventurado...»] ff. $133 \mathrm{v}-134 \mathrm{v}$.

VL 134. Al Marqués de Tarifa. Tercetos [«Entre las cosas dignas de memoria...»] ff. $134 \mathrm{v}-137 \mathrm{v}$.

VL 135. A la Marquesa de Tarifa, doña Ana Téllez Girón. Tercetos [«A ti, suprema y única doña Ana...»] ff. 137v-139r.

VL 136. Al Cardenal Ascanio Colona, Virrey de Aragón. Tercetos [«Del secol nostro onor, Principe sacro...»] ff. 139r-140v.

$V L$ 137. Sestina [«Entre tanto que el mundo ocupa el mundo....»] ff. 141r-v.

$V L$ 138. Sestina [«Es la vida mortal, bien como el tiempo...»] ff. $141 \mathrm{v}-142 \mathrm{v}$.

VL 139. A la política o República de Don Bernardino de Mendoza. Soneto [«Cuanto del universo el globo encierra...»] ff. 142v-143r.

$V L 140$ Soneto [«Esta vida mortal paso en silencio...»] f. 143r.

$V L$ 141. Soneto [«Dichoso aquel varón que se retira...»] ff. 143r-v.

$V L$ 142. Soneto [«Culpo el ingenio ya, ya el arte acuso...»] ff. $143 \mathrm{v}-144 \mathrm{r}$.

$V L$ 143. Soneto [«¿Podrá con sabia mano por ventura...?»] f. 144r.

VL 144. A Doña Luisa de Tejada. Soneto [«Cristal, púrpura, rosa y azucena...»] ff. 144r-v.

$V L$ 145. Soneto [«Si sube al sumo grado de privanza...»] ff. $144 \mathrm{v}-145 \mathrm{r}$.

$V L$ 146. Soneto [«Soberbios arcos, ínclitas ruinas...»] f. 145r.

$V L$ 147. Soneto [«Alto templo sin par de Guadalupe...»] ff. 145r-v.

$V L$ 148. Soneto [«Tú, que con agua cristallina y pura...»] ff. $145 \mathrm{v}-146 \mathrm{r}$.

$V L$ 149. Soneto [«Da el arte un don, da un don naturaleza...»] f. 146r.

$V L$ 150. Soneto [«Contemplando tu ser, de mí me quejo...»] ff. 146r-v.

$V L$ 151. Soneto [ «O sueño dulce, olvido de los males...»] ff. 146v-147r.

$V L$ 152. Soneto. [«La edad gallarda jovenil ardiente...»] f. $147 \mathrm{r}$.

$V L$ 153. Soneto [«El muro de la grande Babilonia...»] ff. 147r-v.

$V L$ 154. Soneto [«Tenga Real Corona, Imperial Verga...»] ff. $147 \mathrm{v}-148 \mathrm{r}$. 
VL 155. A Don Pedro de Granada. Soneto [«Del edificio del tebario muro...»] f. $148 \mathrm{r}$.

VL 156. Compendio del Arte Poética. A Juan de Velasco, Condestable de Castilla [«Es la poesía imitadora única...»] ff. $148 \mathrm{v}-151 \mathrm{v}$.

VL 157. A San Antonio de Pádua. Soneto [«La posesión se os debe de derecho...»] ff. $151 \mathrm{v}-152 \mathrm{r}$.

VL 158. A San Pedro. Soneto [«Pescador, y pastor, que abriendo el cielo...»] ff. $152 \mathrm{r}-\mathrm{v}$.

$V L$ 159. Soneto [ $« \mathrm{O}$ dura edad de hierro, que desprecia...»] f. 152v.

$V L$ 160. Soneto [«Con suspiros el aire enciende Dido...»] f. $153 \mathrm{r}$.

$V L$ 161. Soneto [«La noche trueco el pensamiento en sueño....»] ff. 153r-v.

$V L$ 162. Soneto [«Si es la vida mortal paso y camino...»] f. $153 \mathrm{v}$.

$V L$ 163. Soneto [«En las aras de amor, en sus altares...»] f. 154r.

$V L$ 164. Soneto [«Crespo, rico, gentil, rubio cabello...»] ff. 154r-v.

$V L$ 165. Soneto [«Ronco cisne será, muda sirena...»] f. 154v.

$V L$ 166. Soneto [« Ya magnánimo, altivo osó Fetonte...»] f. 155r.

$V L$ 167. Soneto [«No toquen vuestras manos, os aviso...»] ff. 155r-v.

$V L$ 168. Soneto [«Basta, tirano amor, basta, cruel, basta...»] ff. $155 \mathrm{v}-156 \mathrm{r}$.

VL 169. A Doña Francisca Osorio, Señora de Valdonquillo. Soneto [«Sujeto singular de hermosura...»] ff. 156r-v.

$V L$ 170. Soneto [«Breve don, corto bien, vana privanza...»] f. 156v.

VL 171. A los compañeros de San Mauricio, en Valladolid. Soneto [«Popol fedele a celebrare acinto...»] f. $157 \mathrm{r}$.

VL 172. Canción a los mismos dos Santos [«Si en aquella primera antigua guerra...»] ff. $157 \mathrm{v}-159 \mathrm{r}$.

VL 173. Beatus ille, qui procul negotiis. [«Dichoso aquel que libre de los tráfagos...»] ff. $159 \mathrm{v}-161 \mathrm{v}$.

$V L$ 174. Soneto [«Preso está de monte áspero pendiente...»] f. $161 \mathrm{v}$.

$V L$ 175. Soneto [«Si altivo levanté soberbio vuelo...»] f. 162r.

VL 176 De Don Álvaro de Zúniga, Procurador de Cortes de Salamanca. Soneto [«Si alguna vez peligro a noble pecho...»] f. 162v.

$V L$ 177. Respuesta [«Si navegáis de amor por el estrecho...»] f. 163r.

[colofón] En Madrid, por Juan de la Cuesta. Año MDCVI. f. 163 v.

\section{EL PATRÓN DE ESPAÑA}

El Patrón de España de Cristóbal de Mesa. Al Rey Don Felipe Tercero Nuestro Señor. Año [escudo] 1612. Con Privilegio. En Madrid. Por Alonso Martín. A costa de Miguel de Siles librero.

8 hs. +232 fols.

Suma del Privilegio (Antonio de Olmedo), Madrid, 17 de febrero de 1611, \1 1v. 
Tassa (Antonio de Olmedo), Madrid, 28 de diciembre de 1611, ๆ 2r.

Erratas (Licenciado Murcia de la Lana), Madrid, 16 de diciembre de 1611, ๆ 2v. Aprobación (El Maestro Fr. Hortensio) 93 r.

Censura (El Maestro Fr. Hortensio) ๆ 3r.

[Dedicatoria] Al Rey don Felipe Tercero N[uestro] S[eñor] [«Cuando estando la corte en Valladolid...»] \ $3 \mathrm{v}$.

A los Letores [《Conforme a la doctrina de Tulio...»] \ 4r-v.

Del Autor al Marqués de Ayamonte. Soneto [«Marqués, de nuestro siglo maravilla...»] ब 5 r.

Don Francisco de Guzmán, Marqués de Ayamonte, nombrado por Virrey de la Nueva España, al Autor. Soneto [«Aunque la ley de la amistad me obliga...»] \ 5v. Del Autor a su Magestad. Canción [«Magnánimo Señor, moderno Atlante...»] 『| 6r$8 \mathrm{v}$.

Elogio del Autor a España. Canción [«O católica España...»] ff. 1r-3v.

Libro Primero del Patrón de España [«Musa, el Patrón de las Españas canta...»] f. $4 \mathrm{r}$.

[nueva portada, sin numerar] Rimas de Cristóbal de Mesa. A don Alonso de Zúñiga y Sotomayor, Duque de Bejar, Marqués de Gibraleón, Conde de Benalcázar, Conde de Bañares, Vizconde de la Puebla de Alcocer, de la Orden del Tussón [escudo] En Madrid. Por Alonso Martín. Año 1611, f. 94r (f. 94v blanco).

[Dedicatoria] Al Excelentíssimo Señor don Alonso de Zúñiga y Sotomayor, Duque de Béjar, Marqués de Gibraleón, Conde de Benalcázar, Conde de Bañares, Vizconde de la Puebla de Alcocer, de la Orden del Tussón [«Si es la poesía pintura que habla, y la pintura poesía muda...»] f. 95r.

A los Lectores [«De los tres estilos, tiene el divino Platón por más perfecto...»] ff. 95v-96r.

$P E$ 1. Al Excelentíssimo Duque de Béjar. Soneto [«Dando en los años buelta al tiempo el cielo...»] f. 96v.

PE 2. Al mismo, yéndose de Béjar a Gibraleón. Soneto [«Príncipe del blasón de la cadena...»] f. $97 \mathrm{r}$.

PE 3. Al mismo, dedicándole la Eneida de Virgilio. Soneto [«Magnánimo Señor, gran Cavallero...»] f. 97v.

PE 4. Al mismo, cuando le dio su Magestad el Tussón. Soneto [«Príncipe excelso, de un Imperio digno...»] f. 98r.

PE 5. Al Excelentíssimo Conde de Lemos. Soneto [«Luz del antiguo gran blasón de Castro...»] f. $98 \mathrm{v}$.

PE 6. Al mismo, en la muerte de su hermano, el Conde de Gelves. Soneto [«Príncipe grande y valeroso, cuando...»] f. 99r.

$P E$ 7. Al mismo, en la misma muerte. Soneto [«Si el de Gelves, claríssimo de Lemos...»] f. 99v.

$P E$ 8. Al mismo, yendo Virrey de Nápoles. Soneto [«La cítara gentil, que en toda parte...»] f. 100r. 
PE 9. Al Duque de Feria, don Lorenzo, que murió en Nápoles, viniendo de Virrey de Sicilia. Soneto [«Pronóstico cruel, triste cometa...»] f. 100v.

PE 10. Al mismo Duque don Lorenzo. Soneto [«En sola tu magnánima persona...»] f. $101 \mathrm{r}$.

PE 11. A don García Manrique, Conde de Ossorno. Soneto [«Después, Señor, que en la ribera amena...»] f. 101v.

$P E$ 12. De don Álvaro de Zúñiga al Autor. Soneto [«En tanto, o Mesa, que de ser Maestro...»] f. 102r.

$P E$ 13. En respuesta del Autor. Soneto [«Don Álvaro de Zúñiga, maestro...»] f. $102 \mathrm{v}$.

$P E$ 14. A una señora. Soneto [«Al son del agua clara en sombra amena...»] f. 103r. $P E$ 15. A la misma señora. Soneto [«La celebrada, noble Silvia mía...»] f. 103v. $P E$ 16. A la misma señora. Soneto [«Si una doliente cítara sonante...»] f. 104r. $P E$ 17. A la misma señora. Soneto [«La esfera de las lúcidas estrellas...»] f. 104v. $P E$ 18. A la misma señora. Soneto [«Ningún gentil espíritu presuma,..»] f. 105r. $P E$ 19. A la misma señora. Soneto [«Señora hermosíssima, entre tanto...»] f. 105v. $P E$ 20. A la misma señora. Soneto [«Señora, sola vos desde la cuna...»] f. 106r.

$P E$ 21. A la misma señora. Soneto. [«Lágrimas sin cesar me tienen ciego...»] f. $106 \mathrm{v}$.

PE 22. A la misma señora. Soneto [«¿Qué sirve dar al vìento mis querellas...»] $\mathrm{f}$. $107 \mathrm{r}$.

$P E$ 23. A la misma señora. Soneto [«Cadena es de diamante el fuerte lazo...»] $\mathrm{f}$. $107 \mathrm{v}$.

$P E$ 24. A la misma señora. Soneto [«Dentro desta profonda cueva escura...»] $\mathrm{f}$. $108 \mathrm{r}$.

$P E$ 25. A la misma señora. Soneto [«Árbol no tiene toda aquesta selva...»] f. 108v. $P E$ 26. A la misma señora. Soneto [«Como la Fénix sois en el mundo una...»] f. $109 \mathrm{r}$.

PE 27. A la misma señora en una ausencia. Soneto [«Cuánto espacio de mar, y cuánta tierra...»] f. $109 \mathrm{v}$.

PE 28. Al señor don Hernando de Toledo, primogénito del Excelentíssimo Duque de Alba. Soneto [«Príncipe, sucessor de aquel que solo...»] f. 110r.

$P E$ 29. Que el varón constante no se dexa vencer del amor. Soneto [«De más de un Capitán Latino o Griego...»] f. 110v.

$P E$ 30. A una señora que nació ribera del Tajo. Soneto [«Tajo, no ya por tus arenas de oro...»] f. $111 \mathrm{r}$.

$P E$ 31. Al laurel, que por ser árbol en que se transformó Dafne, no consiente que se pinte Apolo en sus tablas. Soneto [«Casto laurel, que das triunfal corona...»] f. $111 \mathrm{v}$.

PE 32. Que el tiempo se muda de bien en mal. Soneto [«Este lugar de amena Primavera...»] f. 112r. 
$P E$ 33. De un pastor que compara su amor con varias deidades. Soneto [«Començando a mostrar la luz la Aurora..,»] f. 112v.

$P E$ 34. Va buscando la soledad para lamentarse. Soneto [«Este remoto sitio solitario...»] f. 113r.

$P E$ 35. A una señora hermosa y discreta. Soneto [«Vuestro talle gentil en toda parte...»] f. $113 \mathrm{v}$.

$P E$ 36. A Venus, despidiéndose della. Soneto $[\ll T u$ del tercero cielo deidad santa...»] f. 114r.

$P E$ 37. En la muerte del Marqués de Tarifa. Soneto [«O tú, que caminante peregrino...»] f. $114 \mathrm{r}$.

$P E$ 38. En la muerte de una señora. Soneto [«Cortando la guadaña de la muerte...»] f. $115 \mathrm{r}$.

PE 39. A la misma señora. Soneto [«Alma, que eterna entre las almas santas ...»] $\mathrm{f}$. $115 \mathrm{v}$.

$P E$ 40. A la lira de Orfeo. Soneto [«Tú primera, gentil lira doliente...»] f. 116r.

$P E$ 41. A un pastor que se lamenta de un laurel. Soneto [«Pone un pastor el nombre de Marfira...»] f. 116v.

$P E$ 42. A una señora que se llamava doña Elena. Soneto [«Por una sola Elena el Reino griego...»] f. $117 \mathrm{r}$.

PE 43. A una señora, que se llamava doña Marta. Soneto [«Ya la olvidada ronca lira templo...»] f. $117 \mathrm{v}$.

$P E$ 44. A la misma señora. Soneto [«O quién tuviera estilo soberano...»] f. $118 \mathrm{r}$.

$P E$ 45. A la misma señora. Soneto [«Si esculpe el escultor, si el pintor pinta...»] $\mathrm{f}$. $118 \mathrm{v}$.

$P E$ 46. A la misma señora. Soneto [«Tengo en el alma vuestro rostro escrito...»] $\mathrm{f}$. 119 r.

$P E$ 47. Soneto [«Yo, que en la vida de la corte vana...»]. f. 119v.

$P E$ 48. Soneto [《El que alaba la vida de la corte...»] f. $120 \mathrm{r}$.

$P E$ 49. Soneto [«Vana corte, do el mal se disimula...»] f. $120 \mathrm{v}$.

$P E$ 50. Alabando la pobreza. Soneto [«Santo don de pobreza no entendido...»] f. $121 \mathrm{r}$.

PE 51. En la muerte de doña Teresa de Zúñiga, Duquesa de Arcos. Soneto [«Hoy muestra en este túmulo la muerte...»] f. $121 \mathrm{v}$.

PE 52. A Luis Barahona de Soto, que escrivió Las lágrimas de Angélica, amigo del autor. Soneto [«Yaze aquí Luis de Soto Barahona...»] f. 122r.

$P E$ 53. Al Rector de Villahermosa, con quien el autor tiene antigua amistad. Soneto [《Bartolomé Leonardo de Argensola... »] f. 122v.

PE 54. De Don Francisco de Medrano al autor, habiendo leido su Restauración de España. Soneto [«Hizo astillas el yugo, y la coyunda...»] f. 123r.

PE 55. A Don Antonio de Monroy, señor de Monroy, en la muerte de una hija suya. Soneto [«Cesse el grave dolor y el tierno llanto...»] f. 123v. 
PE 56. A Hernando de Herrera, que comentó a Garcilasso y escrivió Rimas, y La batalla naval, amigo del autor. Soneto [«Aquí yaze Hernando de Herrera...»] f. $124 \mathrm{r}$.

PE 57. A San Lorenzo el Real. Soneto [«Este real sepulcro es donde el censo...»] f. $124 \mathrm{v}$.

PE 58. En la fiesta de la Epifania. Soneto [«Rey soberano, de poder inmenso...»] f. $125 \mathrm{r}$.

$P E$ 59. A san Gerónimo. Soneto [«De la púrpura sacra y sacra pompa...»] f. 125v. $P E$ 60. A nuestra Señora. Soneto [«Con gran razón, Emperatriz del cielo...»] f. $126 \mathrm{r}$.

$P E$ 61. Sestina [《La breve vida de la varia corte...»] ff. 126v-127r.

$P E$ 62. Canción [«Soberano Señor, sacrosanta alma...»] ff. 127v-131r.

PE 63. Al Ilustríssimo señor don Bernardo de Rojas y Sandoval, Cardenal de Toledo. Canción [«Príncipe sacro de las dos Españas...»]. ff. 131v-133v).

PE 64. A san Bruno, fundador de la Orden Cartuxana. Canción [«De aquel santo la vida y muerte santa...»] ff. 134r-136r.

PE 65. A Don Alonso de Zúñiga y Sotomayor, Duque de Béjar. Tercetos [«Aunque en causas de Príncipes y Reyes...»] ff. 136v-140r.

PE 66. A Don Gómez Suárez de Figueroa y Córdoba, Duque de Feria, Marqués de Villalba, Señor de las casas de Salvatierra. Tercetos [«Al gran Emperador César Augusto...»]. ff. 140v-144v.

PE 67. A Juan de Velasco, Condestable de Castilla. Tercetos [«Príncipe excelso, sabio Condestable...»] ff. 145r-149v.

PE 68. A Don Pedro de Castro, Conde de Lemos. Tercetos [«Platón, que tuvo el nombre de divino...»] ff. 150r-152r.

PE 69. Al Conde de Lemos, yendo por Virrey de Nápoles. Tercetos [«Gozad, Conde de Lemos, tiempo largo...»] ff. $152 \mathrm{v}-155 \mathrm{v}$.

PE 70. Al Conde de Castro, hermano del de Lemos. Tercetos [«Don Francisco de Castro, ínclito Conde...»] ff. 156r-159r.

PE 71. A Don Francisco de Guzmán, Marqués de Ayamonte. Tercetos [«Buen Marqués Don Francisco de Ayamonte...»] ff. 159v-161v.

PE 72. A Don Francisco Hurtado de Mendoza, Marqués de Almazán. Tercetos [«Ingenio digno de inmortal corona...»] ff. 162r-164r.

PE 73. A Don Antonio Enríquez de Ribera, Marqués de Villanueva del Río. Tercetos [«Claro Marqués, de quien España espera...»] ff. 164v-166v.

PE 74. A Don Rodrigo Pacheco, Marqués de Cerralvo. Tercetos [«Marqués, tres años ha que el Duque nuestro...»] ff. 167r-170r.

PE 75. Respuesta del Marqués. Tercetos [«Bien sabéis, Mesa, cómo el hado nuestro...»] ff. $170 \mathrm{v}-173 \mathrm{v}$.

PE 76. Al Marqués de Cuellar, Don Francisco de la Cueva. Tercetos [«Espíritu gentil, digno de imperio...»] ff. 174r-182v. 
PE 77. A Don Alonso Suárez de Solís, Señor del Villar. Tercetos [«Don Alonso Suárez erudito...»] ff. 183r-187r.

PE 78. A Don Gómez Suárez de Figueroa y Córdova, Duque de Feria. Tercetos [«Ya véis, Duque magnánimo de Feria...»] ff. 187v-193v.

PE 79. A Tomás Hernández de Medrano, del hábito de San Juan. Tercetos [«Al fin, Tomás Hernández de Medrano...»] ff. I94r-200r.

PE 80. A Luis Barahona de Soto. Tercetos [«Amigo Luis de Soto Barahona...»] ff. $200 \mathrm{v}-204 \mathrm{v}$.

PE 81. A Don Hernando Xara y Mesa, mi sobrino. Tercetos [«Sobrino don Hernando Xara y Mesa...»] ff. 205r-208v.

PE 82. A Don Antonio de Ávila, Conde del Risco. Tercetos [«Conde del Risco, todo el sacro Coro...»] ff. 209r-212v.

PE 83. A Don García Manrique, Conde de Osorno. Tercetos [«Conde excelso del título de Osorno...»] ff. 213r-216r.

PE 84. Al Canónigo Pedro Navarrete, Capellán de su Magestad. Tercetos [«Los años corren ya tres vezes siete...»]. ff. $216 \mathrm{v}-219 \mathrm{v}$.

$P E$ 85. A Doña María de Cárdenas. Octavas [«Único honor de toda Extremadura...»]. ff 220r-229v.

PE 86. De Don Francisco de Medrano. Soneto [«Vos en España sois el que primero...»] f. 230r.

PE 87. [De] (A) Hernando de Cangas. Soneto [«Del cuerpo que cubrió quinientos años...»] f. 230v.

PE 88. Del Padre fray Gabriel de Guevara, de la Orden de San Francisco, tío del autor. Soneto [《Donde entra verdes ovas y espadañas...»] f. $231 \mathrm{r}$.

PE 89. Del Padre fray Tomás de Figueroa, Predicador de la Orden de S.Domingo, primo del autor [«Ya, Mesa, con sonora y clara trompa...»] f. 231v.

PE 90. Del Maestro Francisco de Vergara. Soneto [«Heroico Mesa insigne, en quien el cielo...»] f. $231 \mathrm{r}$.

PE 91. De Rodrigo de Ribera. Soneto [«Cantó ya tu Marón, España, el Marte...»] FIN. f. $232 \mathrm{v}$.

\section{LA ENEIDA}

La Eneida de Virgilio. De Cristóbal de Mesa. Al Rey don Felipe Tercero nuestro señor. Año [escudo] 1615. Con Privilegio. En Madrid. Por la viuda de Alonso Martín. A costa de Domingo Gonçález, mercader de libros.

8 hs. +356 fs.

Suma del Privilegio (Jorge de Tovar), 29 de agosto de 1614, $\uparrow 2$ r.

Tassa (Hernando de Vallejo), 12 de diciembre de 1614, $12 \mathrm{v}$.

Erratas (El licenciado Murcia de la Llana), Madrid, 6 de diciembre de 1614, ๆ 3r.

Aprovación (Fray Diego de Ortigosa), Madrid, 17 de agosto de 1614, \ $3 \mathrm{v}$. 
Aprovación (El licenciado Tribaldos de Toledo), Madrid, 26 de julio de 1614, \ 4r. Aprovación (Arçobispo Obispo de Badajoz), [s.1.] 26 de julio de 1614, $\mid 4 \mathrm{v}$.

[Dedicatoria a Felipe III] [«Señor, Homero en la Ilíada canta la ira de Aquiles...»] \ $5 \mathrm{r}$..

A su Magestad. Octavas [«Magnánimo Señor, que en la alta suerte / de la noble corona y cetro justo...»] $\mid$ | $5 \mathrm{v}$.

Al Lector [ «Yo soy tan enemigo de traducciones, según pierden los idiomas nobles puestos en lenguas vulgares ...»] \ 6r-v.

Vida de Virgilio [« Siendo Pompeyo Magno y Licinio Crasso cónsules, nació Publio Virgilio Marón a quinze de Octubre ...»] \ 7r-8v..

De la Eneida de Virgilio. Octavas [«Yo que versos cantaba antiguamente / con pastoril zampoña en fértil parte ...»] f.1r.

[Anónimo] Soneto [«Despu[é]s que con espíritu divino...»] f. 356v.

\section{LAS ÉGLOGAS Y GEÓRGICAS, Y RIMAS, Y EL POMPEYO}

Las Éclogas y Geórgicas de Virgilio, y Rimas, y el Pompeyo tragedia. De Christóbal de Mesa. A Don Alonso Fernández de Córdoba, y Figueroa, Marqués de Priego, y Montalbán, Señor de la Casa de Aguilar, y Castroelrío, y Villafranca. Año [escudo] 1618. Con Privilegio. En Madrid, por Juan de la Cuesta.

8 hs. +191 fols. $+1 \mathrm{~h}$.

Suma del Privilegio (Martín de Segura), Madrid, 27 de noviembre de 1617, \ 2r.

Fee de erratas (El Licenciado Murcia de la Llana), Madrid, 18 de marzo de 1618, 9 $2 \mathrm{r}$.

Tassa (Martín de Segura), Madrid, 23 de marzo de 1618, \2v.

Aprovación del Licenciado Luis Tribaldos de Toledo. Madrid, 12 de diciembre de 1614 [Rimas y El Pompeyo], \ 3r.

Aprovación del Padre Maestro Fr. Hortensio Felix Paravicino. Madrid, 21 de octubre de 1617 [El Pompeyo, Églogas y Geórgicas], \ 3v.

[dedicatoria] A don Alonso Fernández de Córdoba y Figueroa, Marqués de Priego [«Al fin de las Éclogas y Geórgicas y Rimas verá V. Excelencia una Tragedia...»] ๆ 4r-v

Prólogo al Lector [«Platón, a quien la antigüedad llama Divino, en la República que forma...»] $\uparrow 5$ r.

Elogio a la Casa de Córdova. Canción [«O gran Casa de Priego...»] ब 5v-7r.

[Epigrama latino de Vicente Mariner] Ad clarissimum et doctissimum virum Christophorum de Mesa. Acróstico [«Condidit Hic Radios Ingens Sapientia Tecum...»] \ 7v.

Al Ilustrísimo Cardenal de Toledo, del Autor, cuando hizo las obras que van en este libro para las fiestas del Sagrario de Toledo. Soneto: «Si con la sacra púrpura y capelo...» ๆ $8 \mathrm{r}$ 
Al Marqués de Priego. Octavas [«La selvas y los célebres pastores...»] ๆ 8v.

Écloga primera. Melibeo y Títiro. Octavas [«Mel. Títiro, tú que con silvestre avena... »] f. $1 \mathrm{r}$.

Libro Primero de las Geórgicas de Virgilio [«Que haga fértil sementera bella...»] f. $31 \mathrm{v}$.

EG1. [sin portadilla] Horatius. Beatus ille, qui procul negotiis [«Dichoso el que alexado...] ff. $109 \mathrm{r}-110 \mathrm{v}$.

$E G$ 2. Soneto. [ O para siempre antigüedad sagrada...»] f. $111 \mathrm{r}$.

EG 3. Al Marqués de Sieteiglesias. Soneto [«Hércules nuevo al Sandoval Atlante...»] ff. 111r-v.

$E G$ 4. Soneto [« Este mar bravo, que soberbio baña...»] f. 111v.

EG 5. Al Marqués de Villalba. Soneto [«Príncipe excelso, en tierna edad pequeño...»] f. 112 r.

EG 6. Al Mismo. Soneto [«Con el del grande abuelo ínclito nombre...»] ff. 112r-v .

EG 7. Al mismo. Soneto [«Aumenta el cielo el próspero destino...»] f. 112v.

$E G$ 8. Al Conde de Lemos. Soneto [«Ya se llega, señor, ya viene el día...»] f. 113r.

$E G$ 9. Al mismo. Soneto [«Si elocuentes retóricos facundos...»] ff. 113r-v.

$E G$ 10. Soneto [«Ofrezco a tu deidad, sacro Neptuno... » f. 113v.

$E G$ 11. Al Conde de Castro. Soneto [«Si en la santa ciudad, reina del mundo...»] f. $114 \mathrm{r}$.

EG 12. Al Duque de Béjar. Soneto [«Gustad, señor, de aquesta vuestra villa...»] ff. $114 \mathrm{r}-\mathrm{v}$.

$E G$ 13. Al mismo. Soneto [«Si yo tuviera espíritu divino...»] f. 114v.

$E G$ 14. Al mismo. Soneto [«A los cavallos, que en la cuarta Esfera...»] f. 115r.

EG 15. Al mismo. Soneto [«Lunes, mediado Octubre, una mañana...»] ff. 115r-v.

EG 16. A la Duquesa de Béjar. Soneto [«Si Timantes pintó, si pintó Apeles...»] f. $115 \mathrm{v}$.

EG 17. A la misma señora. Soneto [ $« \mathrm{Al}$ mundo en voluntario cautiverio...»] f. 116r. $E G$ 18. A la misma señora. Soneto [«Naturaleza, madre de las cosas...»] ff. 116r-v.

EG 19. Al Duque de Feria. Soneto.[«Cua[n]do dais la obediencia a Paulo quinto...»] f. 116v.

EG 20. Al mismo. Soneto [«Príncipe excelso, a toda Francia espanta»] (f. 117r)

$E G$ 21. Al mismo. Soneto [«El principio y el fin mirando Iano...»] ff. 117r-v.

$E G$ 22. Al mismo. Soneto [«Del nuevo cargo os dé la norabuena...»] f. $117 \mathrm{v}$.

EG 23. A Don Francisco de Silva. Soneto [«Siendo el Príncipe tú, siendo el Mecenas...»] f. $118 \mathrm{r}$.

EG 24. A la Academia de su casa. Soneto [«Para alabar tan célebre Museo...»] ff. $118 \mathrm{r}-\mathrm{v}$.

EG 25. Al mismo. Soneto. [«Sacro Tajo, que das arenas de oro...»] f. 118v. EG 26. Al Marqués de Belmar. Soneto [«Si después que a la rica Señoría...»] f. $119 \mathrm{r}$. 
EG 27. A Don Álvaro de Çúñiga. Soneto [«Si ya del Mincio en la ribera amena... »] ff. $119 \mathrm{r}-\mathrm{v}$.

EG 28. A D. Juan de Fonseca. Soneto [«Don Juan insigne y claro de Fonseca...»] f. $119 \mathrm{v}$.

EG 29. Al mismo. Soneto [«¿Quién será tan pacífico y flemático...?»] f. 120r.

EG 30. Al Arçobispo de Santiago. Soneto [«Insigne honor del nombre de Guevara...»] ff. 120r-v.

EG 31. Al Licenciado Páez Osorio. Soneto [«Si celebrando al gran Trajano y Nerva...»] f. 120v.

EG 32. A un sobrino de Luis Barahona. Soneto [«Este, que sale a luz, cisne canoro...»] f. $121 \mathrm{r}$.

EG 33. Soneto [«Las armas del los Duques de Bergança...»] ff. 121r-v.

$E G$ 34. Horatius. O navis. Soneto [«O Nave, no te ves ya falta de una...»] f. $121 \mathrm{v}$. EG 35. Del mismo argumento. Soneto [«O Nave, cuando el cielo se revuelva..»] f. $122 \mathrm{r}$.

EG 36. A la ciudad de Sevilla. Soneto [«Ínclita, noble, y próspera Sevilla»] ff. $122 \mathrm{r}-\mathrm{v}$.

$E G$ 37. Soneto [«No hay quien contento esté con el estado...»] f. 122v.

$E G$ 38. Soneto [«Estas sacras ruinas y antiguallas...»] f. $123 \mathrm{r}$.

EG.39. Soneto [«Este campo, que fue ciudad de Marte...»] ff. 123r-v.

$E G$ 40. Soneto [«En la verde y florida Primavera...»] f. $123 \mathrm{v}$.

$E G$. 41. Soneto [«Larga esperança, sueño del despierto...»] f. 124r.

$E G$ 42. Soneto [«Vuélveme a la primera vida pobre...»] f. 124r-v.

$E G$. 43. Soneto [ ( O Venturosa edad primera de oro...»] f. 124v.

$E G$ 44. Soneto [ "Aunque es el don de hermosura breve...»] f. 125r.

$E G$ 45. Soneto [«Dexa la Corte y vanas esperanças...»] ff. 125r-v.

$E G$ 46. Soneto [«Por un estéril, áspero desierto...»] f. 125v.

$E G$ 47. Soneto [«Siempre me fue contraria la fortuna »] f. 126r.

$E G$ 48. Soneto [« En este sitio solitario, donde...»] ff. 126r-v.

$E G$ 49. Soneto [ " Tal vez el son de mi silvestre avena...»] f. 126v.

EG 50. Soneto [« Si penas el espíritu padece...»] f. 127r.

$E G$ 51. Soneto [«Cuando contemplo el falso honor humano...»] ff. 127r-v.

$E G$ 52. Soneto [«Cuando contemplo el breve espacio incierto...»] f. $127 \mathrm{v}$.

EG 53. A San Gerónimo. Soneto [«Gran luz, Sol nuevo, espíritu divino...»] f. 128r.

EG 54. Al mismo Santo. Soneto [«Coluna de la Iglesia militante...»] ff. 128r-v.

EG 55. Al mismo Santo. Soneto [«Dexando la romana Corte varia...»] f. 128v.

$E G$ 56. Soneto [«Ya desassí del cuello el grave yugo...»] f. 129r.

$E G$ 57. Soneto [«El valor del varón fuerte y constante...»] ff. 129r-v.

$E G$ 58. Soneto [«Después que vario mar y tierra varia...»] f. 129v.

$E G$. 59. Soneto [«Discreta, y hermosísima doña Ana...] f. 130r.

EG 60. Al Duque de Feria. Soneto [«Pues con sacra señal el pecho marcas...»] ff. 130r-v. 
$E G$ 61. Soneto [«No más de soto en soto, y selva en selva...»] f. 130v.

EG 62. Al Cardenal de Altamira. Soneto [«Vuelve de nuevo al olvidado canto ...»] f. $131 \mathrm{r}$.

EG 63. Al Duque de Alcalá. Soneto [«A ti, de nuestra edad nuevo Mecenas, ...»] ff. $131 \mathrm{r}-\mathrm{v}$.

$E G$ 64. Soneto [«Entre el sueño y temor dudosa, incierta...] f. 131v.

$E G$ 65. Soneto [« Pinte de un buen amante Ovidio en su arte...»] f. 132r.

EG 66. Al Condestable de Nápoles. Soneto [«Noble, antigua familia de Colona...»] ff. $132 \mathrm{r}-\mathrm{v}$.

$E G$ 67. Soneto [«Amor, he hecho yo solene voto...»] f. $132 \mathrm{v}$.

$E G$ 68. Soneto [«Descubran los artífices noveles...»] f. 133r.

$E G$ 69. Soneto [ « Si a mi devota escribo alguna carta...»] ff. 133r-v.

$E G$ 70. Soneto [« La mortal vida es nave, que navega...»] f. 133v.

$E G$ 71. Soneto [« Silencio mudo, que uno y otro labio...»] f. 134

EG 72. Al Griego. Soneto.[«Al soberano universal Monarca...] ff. 134r-v.

$E G$ 73. Soneto [«Quando voy a subir sobre la luna, ...»] f. 134v.

$E G$ 74. Soneto [«Don Diego pardo, amigo, por nuevo Astro...»] f. 135r.

$E G$ 75. Soneto [«Pasan de juventud los verdes años...»] ff. 135r-v.

$E G$ 76. Soneto [«No puede gobernar un gran Monarca...»] f. 135v.

$E G$ 77. Soneto [«Ribera del Jordán, o en el desierto...»] f. 136r.

$E G$ 78. Soneto [«Si Juan, con alto espíritu divino...»] ff. 136r-v.

EG 79. A San Gerónimo. Soneto [«Si el retórico alaba tu elocuencia...»] f. 136v.

$E G$ 80. Al Duque de Feria. Soneto [«Resplandeciente Sol, único Norte...»] f. 137r.

$E G$ 81. Soneto [ « Si con insigne y soberana pompa...»] ff. 137r-v.

$E G$ 82. Soneto [«Vulcano, con espíritu divino...»] f. 137v.

EG 83. Soneto [« Cardenal illustrísimo de Trejo...»] f. 138r.

$E G$ 84. Soneto [«Mis pensamientos, mis palabras, y otras...»] ff.138r-v.

$E G$ 85. Soneto [« Tú, magnánimo Conde de la Oliva...»] f. 138v.

$E G$ 86. Soneto [« La máquina que da sublime altura...»] f. 139r.

$E G$ 87. Soneto [«O Roma, Emperatriz del universo...»] ff. 139r-v.

$E G$ 88. Soneto [«Si vas, ínclito Conde de Salinas...»] f. 139v.

$E G$ 89. Soneto [«Hizo amor en mi pecho íntima llaga...»] f. 140r.

$E G$ 90. Soneto [«El que cantaba con silvestre avena...»] ff. 140r-v.

$E G$ 91. Soneto [«El nombre de Amarilis le dio a Roma »] f. 140v.

$E G$ 92. Soneto [«No contraria fortuna, o hado adverso...»] f. 141r.

$E G$ 93. Soneto [«Yo voy por este campo solitario »] ff. 141r-v.

$E G$ 94. Soneto [«En Madrid, que debiera ser Atenas...»] f. 141v.

$E G$ 95. Soneto [«La madre tierra para ti sea leve »] f. 142r.

$E G$ 96. Soneto [«Este, que ya por líquido camino...»] ff. 142r-v.

$E G$ 97. Soneto [ «Si a la humana beldad la rosa imita...»] f. 142v.

$E G$ 98. Soneto [«Con la sonora cítara doliente...»] f. 143r.

$E G$ 99. Soneto [«Uno, porque da vuelta al Astrolabio...»] ff. 143r-v. 
$E G$ 100. Soneto [«Gloria y honor del nombre de Toledo...»] f. 143v.

EG 101. A Francisco de Figueroa. Soneto [«Gloria de España, honor de su Corona...»] f. 144r.

EG 102. Elogio a los Duques de Feria. Octavas reales [«En el Reino, que en tres puntas se parte...»] ff. $144 \mathrm{v}-150 \mathrm{r}$.

EG 103. Para la fiesta del sagrario de Toledo. Octavas reales [«Desde el reino inmortal del Rey Eterno... »] ff. 150v-153r.

EG 104 Al Ilustrísimo Cardenal de Toledo. Canción [«En el triunfo, y célebre trofeo...»] ff. $153 \mathrm{v}-155 \mathrm{v}$.

EG 105. Elogio en las tablas poéticas del Licenciado Francisco de Cascales. Canción [«La divina poesía ...»] ff. 155v-157v.

EG 106. Al Duque de Feria. Canción [«Los antiguos anales... »] ff. 157v- 159v.

EG. El Pompeyo. Tragedia ff. 160r-191v.

[colofón] En Madrid. Por Juan de la Cuesta. Año M.DC.XVIII. f. 192 r.

\section{Tabla de primeros versos}

A beber apostaron con dos nueces ( $V L$ 50, ff. 73r-v).

A los cavallos, que en la cuarta Esfera $(E G 14$, f. 115 r)

A ti, de nuestra edad nuevo Mecenas ( $E G$ 63, ff. 131r -v )

A ti, suprema y única doña Ana (VL 135, ff. 137v- 139r).

Adiós, amiga solitaria selva ( $V L$ 52, f. 74r).

Al fin, Tomás Hernández de Medrano (PE 79, ff. 194r-200r).

$\mathrm{Al}$ gran Emperador César Augusto (PE 66, ff. 140v-144v).

Al gran Rey, gran Filipe, gran Monarca (VL 121, ff. 118r-v).

Al mundo en voluntario cautiverio ( $E G 17$, f. 116$)$

Al soberano, universal Monarca ( $E G 72$, ff. $134 \mathrm{r}-\mathrm{v})$

Al son del agua clara en sombra amena ( $P E$ 14, f. 103r).

Al Tajo altivo, que con urna de oro (VL 86, ff. 104v-105r).

Al tiempo que la fértil Primavera (VL 126, ff. 120r-v).

Alma noble, si en voz, si en son, si en rima ( $V L$ 96, ff. 108v-109r).

Alma, que eterna entre las almas santas ( $P E$ 39, f. 115v).

Alto templo sin par de Guadalupe (VL 147, ff. 145r-v).

Amigo Luis de Soto Barahona (PE 80, ff. 200v-204v).

Amor, es un alegre pensamiento ( $V L 2$, ff. 57r-v).

Amor, he hecho yo solene voto ( $E G 67$, f. 132 v)

Amor hizo en mi alma una ancha puerta ( $V L 3$, ff. $57 \mathrm{v}-58 \mathrm{r}$ ).

Ande ufano el privado poderoso ( $V L$ 81, f. 103r).

Antes que de la vida el tiempo breve (VL 58, f. 76r).

Aquel Norte de Italia, única joya ( $V L$ 94, f. 108r).

Aquí yaze Hernando de Herrera (PE 56, f. 124r). 
Árbol no tiene toda aquesta selva (PE 25, f. 108v).

Arde en mi pecho un amoroso fuego ( $V L 12$, ff. 60v-61r).

Aumenta el cielo el próspero destino ( $E G 7$, f. 112 v)

Aunque en causas de Príncipes y Reyes (PE 65, ff. 136v-140r).

Aunque es el don de la hermosura breve ( $E G 44$, f. 125 r)

Aunque lo que al valor vuestro se debe ( $V L$ 7, f. 59r).

Bartolomé Leonardo de Argensola (PE 53, f. 122v).

Basta, tirano amor, basta, cruel, basta ( $V L 168$, ff. 155v-156r).

Bel foco fiama mole, e dulce lume ( $V L 112$, f. 115r).

Bella, gentil, preciosa Margarita ( $V L$ 5, ff. 58r-v).

Bellísima Isabel, cuya hermosura ( $V L 59, \mathrm{ff} .76 \mathrm{v}-83 \mathrm{v}$ ).

Betis, que caudalosa, ancha corriente (VL 22, f. 64r).

Breve don, corto bien, vana privanza (VL 170, f. 156v).

Buen Marqués Don Francisco de Ayamonte (PE 71, ff. 159v-161v).

Burlóme amor con esperanza incierta (VL 34, f. 68r).

Cadena es de diamante el fuerte lazo $(P E 23, \mathrm{f} .107 \mathrm{v})$.

Cardenal ilustrísimo de Trejo ( $E G$ 83, f. 138 r)

Casto laurel, que das triunfal corona ( $P E$ 31, f. 111v).

Católico gran Príncipe, que al yugo (VL 107, f. 113r).

Cesse el grave dolor y el tierno llanto ( $P E$ 55, f. 123v).

Claro Marqués, de quien España espera ( $P E 73$, ff. 164v-166v).

Coluna de la Iglesia Militante ( $E G 54$, f.128r-v)

Comenzando a mostrar la luz la Aurora ( $P E$ 33, f. 112v).

Como cuando el timón pierde el Piloto ( $V L$ 43, f. 71r).

Como la Fénix sois en el mundo una ( $P E$ 26, f. 109r).

Con el del grande abuelo ínclito nombre (EG 6, ff. 112r-v)

Con gran razón, Emperatriz del cielo ( $P E$ 60, f. 126r).

Con la sonora cítara doliente ( $E G$ 98, f. 143r)

Con suspiros el aire enciende Dido (VL 160, f. 153r).

Conde del Risco, todo el sacro Coro (PE 82, ff. 209r-212v).

Conde excelso del título de Osorno (PE 83, ff. 213r-216r).

Contemplando tu ser, de mí me quejo (VL 150, ff. 146r-v).

Cortando la guadaña de la muerte ( $P E$ 38, f. 115r).

Crespo, rico, gentil, rubio cabello (VL 164, ff. 154r-v).

Cristal, púrpura, rosa y azucena (VL 144, ff. 144r-v).

Cual el sutil Astrólogo que solo (VL 79, ff. 102r-v).

Cuando contemplo el breve espacio incierto $(E G 52$, f. $127 \mathrm{v})$

Cuando contemplo el falso honor humano ( $E G$ 51, f. 127r-v)

Cua[n]do dais la obediencia a Paulo quinto ( $E G 19$, f. 116 v)

Cuando en la eternidad del tiempo pienso (VL 129, ff. 121r-v). 
¿Cuándo ha de ser aquel dichoso día? ( $V L$ 20, ff. 63r-v).

Cuando la edad, de bienes robadora (VL 38, ff. 69r-v).

Cuando voy a subir sobre la Luna $(E G 73$, f. $134 \mathrm{v})$

Cuando ya tus cabellos y tus ojos ( $V L 33$, ff. 67v- 68r).

Cuanto del universo el globo encierra ( $V L$ 139, ff. 142v- 143r).

Cuánto espacio de mar, y cuánta tierra $(P E 27$, f. 109v).

Cuanto más vuelen los ligeros cielos (VL 15, f. 61v).

Cuanto procuro más celebrar una (VL 26, ff. 65r-v).

Cuarto Felipe, nieto al gran Segundo (VL 95, ff. 108r-v).

Culpo el ingenio ya, ya el arte acuso (VL 142, ff. 143v-144r).

Da el arte un don, da un don naturaleza (VL 149, f. 146r).

Dando en los años buelta al tiempo el cielo ( $P E$ 1, f. 96v).

Darte alabanzas, ínclita Princesa (VL 90, ff. 106-v).

De amor en la agradable compañía ( $V L 27$, ff. 65v- 66r).

De aquel santo la vida y muerte santa ( $P E$ 64, ff. 134r-136r).

De Capitán dio a César nombre el mundo ( $V L$ 124, ff. 119r-v).

De la púrpura sacra y sacra pompa (PE 59, f. 125v).

De más de un Capitán Latino o Griego (PE 29, f. 110v).

De un pensamento en otro pensamento ( $V L 4$, f. 58 r).

Del edificio del tebario muro ( $V L 155$, f. 148r).

Del nuevo cargo os dé la norabuena ( $E G 22$, f. 117 v)

Del presente al antiguo Siglo de Oro ( $V L$ 24, ff. 64v- 65r).

Del secol nostro onor, Principe sacro ( $V L$ 136, ff. 139r-140v).

Dentro desta profunda cueva escura ( $P E$ 24, f. 108r).

Descubran los artífices noveles ( $E G 68$, f. $133 \mathrm{r})$

Desde el reino inmortal del Rey Eterno ( $E G 103$, ff.150v-153r)

Después que vario mar, y tierra varia $(E G 58, \mathrm{f} .129 \mathrm{v})$

Después, Señor, que en la ribera amena $(P E 11, f .101 \mathrm{v})$.

Dexa la corte, y vanas esperanças ( $E G 45$, ff. $125 \mathrm{r}-\mathrm{v})$

Dexando la Romana Corte varia ( $E G 55$, f. $128 \mathrm{v})$

Diácono español que al mundo ciego ( $V L 128, \mathrm{f} .121 \mathrm{r})$.

Dichoso aquel que libre de los tráfagos (VL 173, ff. 159v-161v).

Dichoso aquel varón que se retira ( $V L$ 141, ff. 143r-v).

Dichoso el que alejado ( $E G 1$, ff. 109r-110v)

Discreta y hermosísima doña Ana ( $E G 59$, f. 130 r)

Doma un niño gigante un lince ciego ( $V L 46, f$. 72r).

Don Alonso Suárez erudito ( $P E$ 77, ff. 183r-187r).

Don Álvaro de Zúñiga, maestro ( $P E$ 13, f. 102v).

Don Diego Pardo amigo, por nuevo Astro ( $E G 74$, f. 135 r)

Don Francisco de Castro, ínclito Conde ( $P E$ 70, ff. 156r-159r).

Don Iuan insigne y claro de Fonseca ( $E G 28$, f. 119 v) 
Doña de gran valor, alta corona (VL 91, ff. 106v-107r).

El fin porque se mueve el sabio y fuerte ( $V L 48$, ff. $72 \mathrm{v}-73 \mathrm{r}$ ).

El muro de la grande Babilonia (VL 153, ff. 147r-v).

El nombre de Amarilis le dio a Roma ( $E G$ 91, f. 140v)

El principio y el fin mirando Iano ( $E G 21$, ff.117r-v )

El que alaba la vida de la corte ( $P E 48$, f. 120 r).

El que cantaba con silvestre avena ( $E G 90$, ff. 140r-v)

El que con admirable magisterio ( $V L$ 80, ff. $102 \mathrm{v}-103 \mathrm{r}$ ).

El tempestuoso invierno escuro y cano ( $V L$ 44, ff. $71 \mathrm{r}-\mathrm{v}$ ).

El tiempo en varios pensamientos gasto ( $V L 45$, ff. $71 \mathrm{v}-72 \mathrm{r}$ ).

El tierno canto, y plácidas querellas ( $V L 60$, ff. $84 \mathrm{r}-92 \mathrm{v})$.

El valor del varón fuerte, y constante ( $E G 57$, f. 129r-v)

En cada mano tiene la fortuna ( $V L 73$, ff. 100r-100v).

En el reino, que en tres puntas se parte (EG 102, ff. 144v-150r)

En el triunfo y célebre trofeo ( $E G 104$, ff. $153 \mathrm{v}-155 \mathrm{v})$

En este sitio solitario, donde ( $E G 48$, ff. 126r-v)

En la tormenta, a quien amor me entrega (VL 37, f. 69r).

En la verde, y florida Primavera ( $E G 40$, f. $123 \mathrm{v}$ )

En las aras de amor, en sus altares (VL 163, f. 154r).

En Madrid, que debiera ser Atenas ( $E G$ 94, f. 141v)

En medio del discurso de mi vida (VL 69, f. 99r).

En sola tu magnánima persona ( $P E$ 10, f. 101r).

En tanto que el color de nieve y grana (VL 31, f. 67r).

Entre el sueño y temor dudosa incierta $(E G 64$, f. 131v)

Entre las cosas dignas de memoria (VL 134, ff. 134v-137v)

Entre tanto que el mundo ocupa el mundo ( $V L 137$, ff. 141r-v).

Es la Poesía imitadora única (VL 156, ff. 148v-151v).

Es la vida mortal, bien como el tiempo ( $V L$ 138, ff. 141v-142v).

España mía, siento y lloro en vano ( $V L$ 130, ff. 121v-124r).

Espíritu gentil, digno de imperio ( $P E$ 76, ff. 174r-182v).

Espíritus gentiles que a mi canto ( $V L 1$, f. $57 \mathrm{r})$.

Esta desierta y solitaria tierra ( $V L 67$, ff. $98 \mathrm{r}-\mathrm{v})$.

Esta vida mortal paso en silencio ( $V L$ 140, f. 143r).

Estampa singular de hermosura ( $V L$ 8, ff. 59r-v).

Estas sacras ruinas, y antiguallas $(E G 38, \mathrm{f} .123 \mathrm{r}$ )

Este campo, que fue ciudad de Marte ( $E G 39$, ff. 123r-v)

Este lugar de amena Primavera ( $P E$ 32, f. 112r).

Este mar bravo, que soberbio baña $(E G 4, f .111 \mathrm{v})$

Este real sepulcro es donde el censo $(P E$ 57, f. 124v).

Este remoto sitio solitario ( $P E$ 34, f. 113r).

Este, que sale a luz, cisne canoro ( $E G 32$, f. 121r) 
Este, que ya por líquido camino ( $E G 96$, ff. 142 r-v)

Finge la antigüedad al grande Atlante ( $V L 10$, f. 60 r).

Flaco ingenio, mal verso, estilo rudo ( $V L$ 28, f. 66r).

Fue Filipe sol nuevo en Ocidente ( $V L$ 120, ff. 117v-118r).

Gloria y honor del nombre de Toledo (EG 100, f. 143v)

Glorioso Capitán, digno del canto (VL 84, f. 104r).

Gozad, Conde de Lemos, tiempo largo ( $P E$ 69, ff. 152v-155v).

Gran Don Diego de Córdoba, a ti solo (VL 99, f. 110r).

Gran luz, sol nuevo, espíritu divino ( $E G 53$, f. 128 r)

Gusta mi dama que la sirva y ame ( $V L 40$, f. 70 r).

Gustad, señor, de aquesta vuestra villa ( $E G 12$, ff. 114r-v)

Hércules nuevo al Sandoval Atlante ( $E G 3$, ff. $111 \mathrm{r}-\mathrm{v}$ )

Hizo amor en mi pecho íntima llaga ( $E G 89$, f. 140r)

Hojeando el cuaderno de mi vida ( $V L$ 72, f. 100r).

Hoy el cuarto Filipo Filiberto (VL 98, f. 109v).

Hoy muestra en este túmulo la muerte $(P E 51, f .121 \mathrm{v})$.

Huyendo de los ojos de las gentes (VL 74, ff. 100v-101r).

Ínclita, noble, y próspera Sevilla $(E G 36,122 \mathrm{r}-\mathrm{v})$

Ingenio digno de inmortal corona (PE 72, ff. 162r-164r).

Insigne honor del nombre de Guevara (EG 30, ff. 120r-v)

Junto a los claros ríos ( VL 132, ff. 132v-133v).

Junto es cruel y plácida Sirena ( $V L 16$, f. 62 r).

La antigüedad llama a Platón divino ( $V L \uparrow 7 \mathrm{r})$.

La breve vida de la varia corte (PE 61, ff. 126v-127r).

La celebrada, noble Silvia mía (PE 15, f. $103 \mathrm{v})$.

La cítara gentil, que en toda parte ( $P E 8$, f. 100r).

La divina poesía ( $E G 105$, ff. $155 \mathrm{v}-157 \mathrm{v}$ )

Là dove il grande in lira, in cetra, in tromba $(N T$ \v; $V L$ 110, ff.114r-v).

La edad gallarda jovenil ardiente ( $V L$ 152, f. 147r).

La esfera de las lúcidas estrellas ( $P E$ 17, f. 104v).

La flor del nombre de Ayax y Jacinto (VL 125, ff. 119v-120r).

La madre tierra para ti sea leve ( $E G 96, \mathrm{f} .142 \mathrm{r})$

La máquina que da sublime altura ( $E G 86$, f.139r)

La mortal vida es nave, que navega ( $E G 70$, f.133v)

La noche trueco el pensamiento en sueño ( $V L$ 161, ff. 153r-v).

La posesión se os debe de derecho (VL 157, ff. 151v-152r). 
La que me concedéis laurea corona ( $V L$ 87, ff. 105r-v).

La vida solitaria del desierto (VL 104, ff. 111v-112r).

La vuelta ha dado el cielo al décimo año (VL 61, ff. 93r-v).

Lágrimas sin cesar me tienen ciego (PE 21, f.106v).

Larga esperança, sueño del despierto $(E G 41, \mathrm{f} .124 \mathrm{r})$

Las águilas que el pueblo alto romano $(V L 93, \mathrm{f} .107 \mathrm{v})$.

Las armas de los Duques de Bergança (EG 33, ff. 121r-v)

Las obras que a la fama y la memoria (VL 122, f. $118 \mathrm{v})$.

Las selvas y los célebres pastores $(E G \sqcap 8 \mathrm{v})$

Lejos voy del profundo vulgo incierto ( $V L 65$, ff. 97v-98r).

Los antiguos anales ( $E G 106$, ff. $157 \mathrm{v}-159 \mathrm{v})$

Los años corren ya tres vezes siete ( $P E 84$, ff. $216 \mathrm{v}-219 \mathrm{v})$.

Los dos soles, las dos lámparas claras ( $V L 29$, ff. 66r-v).

Lunes, mediado Octubre, una mañana ( $E G 15$, ff. $115 \mathrm{r}-\mathrm{v})$

Luz del antiguo gran blasón de Castro (PE 5, f. 98v).

Luz del blasón de Córdoba y Cardona (VL 123, f. 119r).

Magnánimo Marqués, nieto y sobrino ( $V L$ 63, f. 97r).

Magnánimo Señor, gran cavallero $(P E 3$, f. 97v).

Magnánimo Señor, moderno Atlante ( $P E$ \ $6 \mathrm{r}-8 \mathrm{v}$ )

Magnánimo Señor, que en la alta suerte $(E N \mid 7 \mathrm{r})$

Marqués, de nuestro siglo maravilla ( $P E \llbracket 5 \mathrm{r}$ )

Marqués, tres años ha que el Duque nuestro (PE 74, ff. 167r-170r).

Mientras debajo de tu Imperio injusto ( $V L 39$, ff. $69 \mathrm{v}-70 \mathrm{r})$.

Mientras en carta, en lienzo, en varia tinta ( $V L 11$, ff. 60r-v).

Miro el turbado mar desde la tierra ( $V L$ 54, ff. 74v-75r).

Mis pensamientos, mis palabras, y otras ( $E G 84$, ff. $138 \mathrm{r}-\mathrm{v})$

Naturaleza, madre de las cosas ( $E G 18$, ff. 116r-v)

Nìngún gentil espíritu presuma ( $P E$ 18, f.105r).

No contraria fortuna, o hado adverso ( $E G 92$, f. 141r)

No hay quien contento esté con el estado ( $E G 37$, f. $122 \mathrm{v})$

No más de soto en soto, y selva en selva ( $E G$ 61, f. 130v)

No puede gobernar un gran Monarca ( $E G 75$, f. $135 \mathrm{v}$ )

No se debe dolor, luto ni llanto ( $V L$ 114, ff. 115v-116r).

No toquen vuestras manos, os aviso (VL 167, ff. 155r-v).

Noble, antigua familia de Colona ( $E G$ 66, ff. 132r-v)

Nuevo Agusto español, nuevo Mecenas ( $V L$ 100, ff. 110r-v).

Nuevos colores busque y nueva tinta (VL 35, ff. 68r-v).

Nunca la antigua ni moderna Roma ( $V L$ 116, ff. 116r-v).

O Betis caudaloso, rey de ríos ( $V L$ 23, ff. 64r-v). 
O bienaventurado ( $V L$ 133, ff. 133v-134v).

O católica España ( $P E$, ff. 1r-3v).

$O$ dura edad de hierro, que desprecia ( $V L 159$, f. $152 \mathrm{v})$.

O gran Casa de Priego ( $E G$ ๆ $5 \mathrm{v}-7 \mathrm{v}$ )

O nave, no te ves ya falta de una $(E G 34, \mathrm{f} .121 \mathrm{v})$

O nave, cuando el cielo se revuelva ( $E G 35, \mathrm{f} .122 \mathrm{r})$

O para siempre antigüedad sagrada $(E G 2$, f. 111 r)

O quién tuviera estilo soberano ( $P E$ 44, f. 118r).

O Roma, emperatriz del universo ( $E G 87$, ff.139r-v)

O sueño dulce, olvido de los males ( $V L$ 151, ff. 146v-147r).

O tú, que caminante peregrino ( $P E 37$, f. 114r).

O Venturosa edad primera de oro $(E G 43$, f. $124 \mathrm{v})$

Ofrezco a tu Deidad, sacro Neptuno (EG 10, f. 113v)

Para alabar tan célebre Museo ( $E G$ 24, ff. 118r-v)

Pasa $n$ apriesa los ligeros días ( $V L$ 76, ff. 101r-v).

Pasan de juventud los verdes años ( $E G 75$, ff. 135r-v)

Pescador y pastor, que abriendo el cielo ( $V L 158$, ff. 152r-v).

Pinte de un buen amante Ovidio en su arte (EG 65, f. 132r)

Platón, que tuvo el nombre de divino ( $P E$ 68, ff. 150r-152r).

¿Podrá con sabia mano por ventura? (VL 143, f. 144r).

Pone un pastor el nombre de Marfira ( $P E$ 41, f. 116v).

Popol fedele a celebrare acinto ( $V L$ 171, f. 157r).

Por la alta sombra de la noche oscura (VL 21, ff. 63v- 64r).

Por un estéril, áspero desierto ( $E G 46$, f. $125 \mathrm{v})$

Por una sola Elena el reino griego ( $P E$ 42, f. 117r).

Preso está de monte áspero pendiente (VL 174, f. 161v).

Príncipe del blasón de la cadena ( $P E$ 2, f. 97r).

Príncipe excelso, a toda Francia espanta ( $E G$ 21, ff. 117r-v)

Príncipe excelso, de un Imperio digno ( $P E 4$, f. 98r).

Príncipe excelso, en tierna edad pequeño ( $E G 5$, f. 112 r)

Príncipe excelso, sabio Condestable ( $P E$ 67, ff. 145r-149v).

Príncipe grande y valeroso, cuando ( $P E$ 6, f. 99r).

Príncipe sacro de las dos Españas ( $P E$ 63, ff. 131v-133v).

Príncipe, sucessor de aquel que solo ( $P E$ 28, f. 110r).

Pronóstico cruel, triste cometa (PE 9, f. 100v).

Pues con sacra señal el pecho marcas $(E G 60$, ff. 130r-v)

Púrpura roja y cárdena azucena ( $V L 118$, f. 117r).

¿Qué sirve dar al vìento mis querellas (PE 22, f. 107r).

¿Quién me dará favor para que cante? ( $V L 42, \mathrm{ff} .70 \mathrm{v}-71 \mathrm{r}$ ).

Quien será tan pacífico y flemático (EG 29, f. 120r) 
Resplandeciente Sol, único Norte ( $E G 80$, f. 137r)

Rey soberano, de poder inmenso ( $P E$ 58, f. 125r).

Ribera del Jordán, o el desierto ( $E G$ 77, f. 136r)

Ronco cisne será, muda sirena (VL 165, f. 154v).

Sacro Tajo, que das arenas de oro $(E G 25$, f. $118 \mathrm{v})$

Salvo en la tierra, al cielo, o mar sagrado ( $V L$ 70, ff. 99r-v).

Santo don de pobreza no entendido ( $P E$ 50, f. 121r).

Señora hermosíssima, entre tanto ( $P E 19$, f. 105v).

Señora, sola vos desde la cuna (PE 20, f.106r).

$\mathrm{Si}$ a la humana beldad la rosa imita $(E G 97$, f. 142v)

$\mathrm{Si}$ a mi devota escribo alguna carta (EG 69, ff. 133r-v)

Si al fin de largo tiempo, al cielo plugo ( $V L$ 71, ff. 99v-100r).

$\mathrm{Si}$ al gran Francisco lloras como a muerto ( $V L$ 117, ff. 116v-117r).

Si altivo levanté soberbio vuelo (VL 175, f. 162r).

¿Si amor me hace osado, por qué temo? (VL 17, ff. 62r- 62v).

Si bien ya con la voz viva no suenas (VL 103, f. 111v).

Si celebrando al gran Trajano y Nerva $(E G 31, f .120 \mathrm{v})$

Si celebró la edad antigua tanto ( $V L 85$, f. $104 \mathrm{v})$.

Si con insigne y soberana pompa ( $E G$ 81, ff. 137r-v)

Si con la sacra púrpura, y capelo $(E G \rrbracket 8 \mathrm{r})$

Si descrivo el sujeto soberano (VL 25, f. 65 r).

Si después que a la rica Señoría ( $E G 26$, f. 119r)

Si el de Gelves, claríssimo de Lemos ( $P E$ 7, f. 99v).

$\mathrm{Si}$ el gran valor, si el rostro peregrino ( $V L 47, \mathrm{ff} .72 \mathrm{r}-\mathrm{v})$.

Si el retórico alaba tu elocuencia ( $E G 79$, f. 136v)

Si elocuentes, retóricos facundos ( $E G 9$, ff. 113r-v)

$\mathrm{Si}$ en aquella primera antigua guerra ( $V L 172$, ff. $157 \mathrm{v}-159 \mathrm{r})$.

Si en el espacio de la edad incierta ( $V L$ 53, ff. 74r-v).

Si en la Santa ciudad, reina del mundo (EG 11, f.114r)

$\mathrm{Si}$ encima de las alas de alto verso ( $V L 51, \mathrm{ff} .73 \mathrm{v}-74 \mathrm{r})$.

Si es la vida mortal paso y camino (VL 162, f. 153v).

Si esculpe el escultor, si el pintor pinta (PE 45, f. 118v).

Si estilo que no fuere soberano ( $V L 57$, ff. $75 \mathrm{v}-76 \mathrm{r}$ ).

Si Juan, con alto espíritu divino ( $E G 78$, ff. 136r-v)

Si la soberbia magestad latina ( $V L 6$, ff. $58 \mathrm{v}-59 \mathrm{r}$ ).

Si las ínclitas obras peregrinas ( $V L 83$, ff. $103 \mathrm{v}-104 \mathrm{r})$.

Si levanto en tu honor alto teatro ( $V L 41, \mathrm{ff} .70 \mathrm{r}-\mathrm{v})$.

Si navegáis de amor por el estrecho (RE 8r-v; VL 177, f. 163r).

Si os tengo amor, por natural instinto ( $V L 56, \mathrm{ff} .75 \mathrm{r}-\mathrm{v})$.

Si penas el espíritu padece $(E G 50,127 \mathrm{r})$ 
Si sube al sumo grado de privanza (VL 145, ff. 144v-145r).

Si Tántalo desea, deseo y siento ( $V L 13$, f. 61r).

Si Timantes pintó, si pintó Apeles (EG 16, f. 115v)

Si una doliente cítara sonante (PE 16, f. 104r).

Si vas, ínclito Conde de Salinas ( $E G$ 88, f. $139 \mathrm{v}$ )

Si ya del Mincio en la ribera amena ( $E G$ 27, ff. 119r-v)

Si yo tuviera espíritu divino ( $E G 13$, f. $114 \mathrm{v})$

Siempre me fue contraria la fortuna $(E G 47$, f. 126r)

Siempre seguí la vida solitaria ( $V L 77$, ff. $101 \mathrm{v}-102 \mathrm{r})$.

Siendo el Príncipe tú, siendo el Mecenas ( $E G$ 23, f. 118r)

Silencio mudo, que uno y otro labio $(E G 71$, f. $134 \mathrm{r})$

Silvia, oyó el cielo, oyó mi ruego el cielo (VL 36, ff. 68v-69r).

Soberano Señor, sacrosanta alma (PE 62, ff. 127v-131r).

Soberbios arcos, ínclitas ruinas ( $V L$ 146, f. 145r).

Sobrino don Hernando Xara y Mesa (PE 81, ff. 205r-208v).

Sois del alto poder grande misterio (VL 92, ff. 107r-v).

Sólo aquel venturoso ( $V L$ 131, ff. 124v-132r).

Soñé, Señora, el más alegre sueño $(V L 9$, ff. $59 \mathrm{v}-60 \mathrm{r})$.

Soto, aquí donde el gran Betis deciende (VL 102, f. 111r).

Sujeto singular de hermosura (VL 168, ff. 156r-v).

Tajo, no ya por tus arenas de oro (PE 30, f. 111r).

Tal valor, tal caudal o gran Mateo (VL 101, ff. 110v- 111r).

Tal vez el son de mi silvestre avena $(E G 49$, f. 126v)

Teatro, Capitolio, Coliseo (VL 82, ff. 103r-v).

Tenga real corona, imperial verga ( $V L 154$, ff. $147 \mathrm{v}-148 \mathrm{r})$.

Tengo en el alma vuestro rostro escrito ( $P E 46, \mathrm{f} .119 \mathrm{r}$ ).

Tiempo fue ya que amor con burla y juego (VL 66, f. 98r).

Tiéneme vuelto amor un breve mundo ( $V L 19$, f. 63r).

Todo al fin tiene fin, todo alto imperio ( $V L 49$, f. 73r).

Todo el tiempo cruel trueca y revuelve ( $V L 68$, ff. $98 \mathrm{v}-99 \mathrm{r})$.

Tu cítara gentil que dulce admira (VL 97, ff. 109r-v).

Tú, de la vida en el espacio incierto ( $V L$ 115, f. 116r).

Tú, del tercero cielo deidad santa ( $P E$ 36, f. 114r).

Tú, Fidelio, con verso peregrino ( $V L$ 127, f. 120v).

Tú, gran Carranza, que andaluz Atlante (VL 105, ff. 112r-v).

Tú, magnánimo Conde de la Oliva (EG 86, f. 138v).

Tú, plateada vega, húmeda luna ( $V L$ 55, f. 75r).

Tú, primera, gentil lira doliente ( $P E 40, \mathrm{f}$. 116r).

Tú, que con agua cristallina y pura ( $V L 148$, ff. $145 \mathrm{v}-146 \mathrm{r}$ ).

Tus siete montes, Roma, en varias rimas $(V L 119$, f. $117 \mathrm{v})$.

Tuve un tiempo y tendré siempre esperanza ( $V L 18$, ff. $62 \mathrm{v}-63 \mathrm{r}$ ). 
Una Diosa nació con Febo en Delo ( $V L$ 30, ff. 66v-67r).

Único honor de toda Extremadura ( $P E$ 85, ff. 220r-229v).

Único sucessor del grande Estado ( $V L$ dedicatoria, f. 56 v).

Uno, porque da vuelta al Astrolabio ( $E G$ 99, ff. 143r-v)

Vana corte do el mal se disimula (PE 49, f. 120v).

Viénese al suelo la alta antigua Troia ( $V L$ 14, ff. 61r-v).

Viste el campo la alegre Primavera (VL 75, f. 101r).

Vivo en cuidado, en pena, en prisión dura ( $V L 32$, ff. 67r-v).

Vos del nombre del que es Christo Atlante ( $V L$ 108, f. 113v).

Voy por aquesta solitaria selva (VL 62, ff. 93v-94v).

Vuelve a su patria, o mar sagrado, a uno ( $V L$ \ 7r-v).

Vuelve de nuevo al olvidado canto ( $E G$ 62, f. 131r)

Vuélveme a la primera vida pobre ( $E G 42$, ff. $124 \mathrm{r}-\mathrm{v})$

Vuestro talle gentil en toda parte $(P E 35, \mathrm{f} .113 \mathrm{v})$.

Vulcano, con espíritu divino ( $E G 82$, f. $137 \mathrm{v})$

Ya desassí del cuello el grave yugo ( $E G 56$, f. 159r)

Ya la olvidada ronca lira templo $(P E 43$, f. $117 \mathrm{v})$.

Ya las reales, ínclitas galeras ( $V L$ 89, f. 106r).

Ya magnánimo, altivo osó Fetonte (VL 166, f. 155r).

Ya me fue favorable la fortuna ( $V L$ 78, f. 102r).

Ya se llega, señor, ya viene el día $(E G 8, \mathrm{f} .113 \mathrm{r})$

Ya véis, Duque magnánimo de Feria $(P E 78$, ff. 187v-193v).

Ya, claro Conde, el grande padre Océano ( $V L$ 88, f. 105v).

Yaze aquí Luis de Soto Barahona (PE 52, f. 122r).

Yo con silencio voy por vida quieta (VL 64, ff. 97r-v).

Yo voy por este campo solitario ( $E G 93$, ff. 141r-v)

Yo, que en la vida de la corte vana $(P E 47$, f. 119v).

\section{Llantos}

Bien puedes tú, llorosa Magdalena (VL, Llanto 4, ff. 29r-38v).

Del africano gran doctor latino (VL, Llanto 6, ff. 46v- 54v).

Del que del gallo al matutino canto ( $V L$, Llanto 3 , ff. 20r- 28v).

Lágrimas, llagas, penitencia canto (VL, Llanto 5, ff. 39r- 46r).

Las lágrimas del Rey profeta canto (VL, Llanto 1, ff. 1r-10r).

Las lágrimas diré de aquellos ojos (VL, Llanto 2, ff. 10v-19v). 


\section{Éclogas}

Agrado a la primera Musa mía (EG, VI, f. 16v)

Concede a mi cantar, sacra Aretusa (EG, X, f. 28v)

Dafnis debaxo acaso de una encina ( $E G, \mathrm{VII}, \mathrm{f} .19 \mathrm{v})$

Dameta, ¿de quién es este ganado? ( $E G$, III, f. $6 \mathrm{v}$ )

¿Dónde vas, Meris? ¿dónde te encaminas? (EG, IX, f. 26v)

El pastor Coridón, con amor ciego ( $E G$, II, f. 4r)

La Musa de Damón y Alfesibeo ( $E G$, VIII, f, 22v)

Musas sicilianas, nuestro canto ( $E G, \mathrm{IV}, \mathrm{f} .11 \mathrm{r})$

O Mopso, siendo diestros igualmente $(E G, \mathrm{~V}, \mathrm{f} .13 \mathrm{r})$

Títiro, tú que con silvestre avena ( $E G, \mathrm{I}, \mathrm{f} .1 \mathrm{r})$

\section{Geórgicas}

Agora he de cantar, o gran Mecenas (EG, L.IV, f.88v)

Cantado he hasta aquí la agricultura (EG, L.II, f. 49 v)

Pales grande, y de Anfriso pastor santo (EG, L.III, f. 68v)

Que haga fértil sementera bella $(E G$, L.I, f.31v) 


\section{Poemas dedicados a Cristóbal de Mesa}

A la orilla del húmedo elemento (NT, f. 325 v, Miguel López de Aguirre). A los filos de aquella ardiente espada (NT, f. 326 v, Francisco Cascales). A los grandes espíritus de Italia (RE, f. 180 v, Hernando de Guzmán). Altivo el Mincio, y con razón contento (NT, f. 324 v, Pedro Ramírez de Guzmán) . Aunque la ley de la amistad me obliga (PE, ๆ 5v, Francisco de Guzmán, Marqués de Ayamonte).

Bien sabéis, Mesa, cómo el hado nuestro (PE 75, ff. 170v-173v, Don Rodrigo Pacheco, Marqués de Cerralvo).

Cantó ya tu Marón, España, el Marte ( $P E$ 91, f. 232v, Rodrigo de Ribera)

De la ciudad que guarda el Mauseolo (NT, f. 325 r; VL 106, ff. 112v-113r, Baltasar de Escobar).

Del cuerpo que cubrió quinientos años ( $P E$ 87, f. 230v, Hernando de Cangas; atribución errónea a Cristóbal de Mesa).

Despu[é]s que con espíritu divino (EN, f. 356 v., Anónimo: ¿Cristóbal de Mesa?).

Doblada debe a vos palma y corona (RE, f. 179 v, Fray Cristóbal de Zafra, Rector del Colegio de San Lorenzo el Real, Primo del autor).

Donde entre verdes ovas y espadañas...»]. ( $P E$ 88, f. 231r, fray Gabriel de Guevara).

El sacro cisne que entre el Mincio y Pado (RE $9 \mathrm{r}$, don Luis Manuel).

En dos poemas de dos Reyes santos ( $R E$ ๆ $7 \mathrm{v}$; VL 109, ff. 113v- 114r, Luis Barahona de Soto).

En tanto, o Mesa, que de ser Maestro (PE 12, f. 102r, Don Álvaro de Zúñiga).

Fama, si sueles con sonora trompa (NT, f. 326r, Lic.do Diego Vélez de Dueñas).

Heroico Mesa insigne, en quien el cielo (PE 90, f. 231r, Francisco de Vergara).

Hizo astillas el yugo, y la coyunda ( $P E$ 54, f. 123r, Francisco de Medrano).

Hoy de los hondos senos del olvido (RE $\uparrow 7 \mathrm{r}$, Francisco de Quevedo).

Ove fia che non giunga e che non versi $(V L \uparrow 7 \mathrm{v}-8 \mathrm{r}$, Camillo Pellegrino $)$.

Quei che con sommo studio il mondo ammira ( NT $₫ 6 \mathrm{r} ; V L 111, \mathrm{f} .114 \mathrm{v}$, Torquato Tasso).

Si alguna vez peligro a noble pecho (VL 176, f. 162v, Álvaro de Zúñiga).

Si de dos griegos canta el griego Homero (RE, f. 180r, Licenciado don Luis Xara, Gobernador de Zafra, Primo del autor).

Sia pur ceraunio scoglio o selce alpina ( $V L \uparrow 8 \mathrm{r}$, Felice Milenzio).

Tal como escuchas, o Alexandro nuevo ( $R E$ ๆ $5 \mathrm{v}$, Doctor Agustín de Tejada y Páez).

Valle, che le tue verdi e ricche sponde (VL 9 8r-v, Giulio Caria).

Venció Pelayo, y para gloria nuestra (RE \ 7r-v, Doctor Fr. Miguel Cejudo, del hábito de Calatrava).

Vivo esempio di gloria, honor di quelli (NT 6v; VL 113, ff. 115r-v, Girolamo Gagliardi). 
Vos en España sois el que primero (PE 86, f. 230r, Francisco de Medrano)

Ya, Mesa, con sonora y clara trompa (PE 89, f. 230v, fray Tomás de Figueroa).

\section{Bibliografía}

CRISTÓBAL DE MESA, Rimas, ed. de Ricardo Senabre, Universitad de Badajoz, 1991 (edición antológica).

ARCE, Joaquín.: Tasso y la poesía española, Planeta, Barcelona, 1973.

ASENSIO, Eugenio, "España en la épica filipina. Al margen de un libro de $\mathrm{H}$. Cidade", en RFE, XXXIII (1949), pp.66-109.

ASENSIO, Eugenio, La fortuna de 'Os Lusiadas' en España (1572-1972), Fundación Universitaria Española, Madrid, 1973.

BEALL, Chandler B.: "Cristóbal de Mesa and Tasso's Rime", en Modern Language Notes, LX, 1945, pp. 469-472.

BERTINI, Giovanni Maria, "Torquato Tasso e il Rinascimento spagnolo", en AA.VV., Torquato Tasso, Marzorati, Milano, 1957, pp.607-671.

BIANCHI, Natascia, "Un episodio della fortuna di Torquato Tasso in Spagna: El Pompeyo di Cristóbal de Mesa", en Encarnación Sánchez García, Anna Cerbo, Clara Borrelli (ed.), Spagna e Italia attraverso la letteratura del secondo Cinquecento. Atti del Colloquio Internazionale, I.U.O., Napoli 21-23 ottobre 1999, Istituto Universitario Orientale, Napoli, 2001, pp. $327-38$

CARAVAGGI, Giovanni, "Evoluzione di un presupposto aristotelico nell'epica ispanica del tardo Rinascimento", en Cultura Neolatina, XXIII-XXIV, 1963-64, pp.18-71.

CARAVAGGI, Giovanni, "Torquato Tasso e Cristóbal de Mesa", en Studi Tassiani, XX, 1970, pp. 46- 85.

CARAVAGGI, Giovanni, Studi sull'epica ispanica del Rinascimento, Università di Pisa, 1974 (sobre C. de Mesa las pp. 225-325).

CARAVAGGI, Giovanni, "Scoperte e conquiste nelle dispute accademiche sul poema eroico", en Theodor Berchem y Hugo Laitenberger (ed.), Lengua y literatura en la época de los descubrimientos. Actas del coloquio internacional, Würzburg, 1992, pp. 147-155.

CARAVAGGI, Giovanni, "Modelli tassiani nell'epica ispanica del Secolo d'Oro", en Daniele Rota (ed.), Tasso e l'Europa, Baroni, Viareggio (Documenta Taxiana, IV), 1996, pp. 61-78.

CARAVAGGI, Giovanni, “Cristóbal de Mesa”, en Voz y Letra, VIII, 2007, pp. 6777, y en Pablo Jauralde Pou (dir.), Diccionario filológico de la literatura española del siglo XVII, Castalia, Madrid, 2010, Vol. I., pp. 980-986. 
CEBRIAN, José, "En torno a una epopeya inédita del siglo XVI: el Hércules animoso de Juan de Mal Lara", en Bulletin Hispanique, 91,1989, pp. 365-393.

CEBRIAN, José, "Sobre Herrera y Mal Lara con un Hércules de por medio", en A.A. V.V, Estado actual de los estudios sobre el Siglo de Oro, I, Salamanca, 1993, pp. 233-244.

CHEVALIER, Maxime, L'Arioste en Espagne (1530-1650). Recherches sur l'influence du "Roland Furieux", Institut d'études ibériques et ibéroaméricaines de l'Université de Bordeaux, Bordeaux, 1966.

COSSUTTA, Fabio, Gli ideali epici dell'Umanesimo e l' Orlando Furioso, Bulzoni, Roma, 1995.

CROCHE DE ACUÑA, Francisco, "Las gestas de la Casa Ducal de Feria en los versos del poeta zafrense Cristóbal de Mesa", en Revista de Estudios Extremeños, LVII, II, 2001, pp. 617-643

DAVIS, Elizabeth B., Myth and Identity in the Epic of Imperial Spain, University of Missouri Press, Columbia and London, 2000.

DRAKE, Gertrude y Forbes, Clarence A., Marco Girolamo Vida's The Christiad, Southern Illinois University Press, 1978.

DURAND, José, "Ercilla y Camões", en IV Centenario de Os Lusiadas de Camões, 1572-1972, Madrid, 1972.

FITTS FINCH, Mary, "Introducción", en Cristóbal de Virués, El Monserrate segundo, Albatros Hispanofilia ediciones, Valencia-Chapel Hill, 1984.

GARROTE BERNAL, Gaspar, Palabras por patrocinio. Cristóbal de Mesa ante el Duque de Béjar (Rimas, 1611), en J. Ignacio Díez (ed.), El mecenazgo literario en la casa ducal de Béjar durante la época de Cervantes, Burgos, Instituto Castellano y Leonés de la Lengua, 2005, pp. 131-171.

GÓMEZ GÓMEZ, Juan María, La imitación de la "Eneida" en "Las Navas de Tolosa". Poema heroico de Cristóbal de Mesa, en César Chaparro Gómez, Manuel Mañas Núñez y Delfín Ortega Sánchez (ed.), "Nvlla dies sine linea". Humanistas extremeños: de la fama al olvido, Universidad de Extremadura, Cáceres, 2009, pp. 115-29.

JAVITCH, Daniel, Proclaiming a Classic: The Canonization of Orlando Furioso, Princeton University Press, 1991.

LARA GARRIDO, José, Los mejores plectros. Teoría y práctica de la épica culta en el Siglo de Oro, Analecta Malacitana, Anejo XXIII, Málaga, 1999.

LÓPEZ PRUDENCIO, José: "Valores olvidados: Cristóbal de Mesa", en Revista del Centro de Estudios Extremeños, XVI, 1942, pp. 165-178.

MAZZOCCHI, Giuseppe, "El Patrón de España" de Cristóbal de Mesa, en Da Virgilio a Marinetti. Tre saggi di comparatistica ispanica, Folini, Casal Noceto, 1990, pp. 9-53, y en Il Confronto Letterario, Pavía, XI, 1994, 22, pp. 335-374. 
NÚÑEZ GONZÁLEZ, Juan María, Cristóbal de Mesa, traductor, en César Chaparro Gómez, Manuel Mañas Núñez y Delfín Ortega Sánchez (ed.), "Nvlla dies sine linea". Humanistas extremeños: de la fama al olvido, Universidad de Extremadura, 2009, pp. 265-80.

PIERCE, Frank, La poesia épica del Siglo de Oro, Gredos, Madrid, 1968.

PIERCE, Frank, "La poesía épica española del Siglo de Oro", en Edad de Oro, IV, 1985, pp. 87-105.

PRIETO, Antonio, "Del ritual introductorio en la épica culta", en Estudios de literatura europea, 1975, pp.15-72.

PRIETO, Antonio, "Origen y transformación de la épica culta en castellano", en Analecta Malacitana, II (1979), pp. 193-243.

PRIETO, Antonio, La poesía española del siglo XVI. Aquel valor que respetó el olvido, Cátedra, Madrid, 1987.

RODRÍGUEZ-MOÑINO, Antonio, "Cristóbal de Mesa. Estudio bibliográfico (1562- 1633)", en Revista de Estudios Extremeños. VI, Badajoz, 1950, pp. 395-501 .

TEIJEIRO FUENTES, Miguel Ángel, Los poetas extremeños del Siglo de Oro, Editora Nacional de Extremadura, Badajoz, 1999.

TEIJEIRO FUENTES, Miguel Ángel, "Los personajes de 'El Pompeyo' de Mesa a la luz de la 'Farsalia' de Lucano", en Lola González (ed.), Estudios sobre el Teatro del Siglo de Oro, Scriptura, Lérida, 2002, núm. 17, p. 319-33 (Número monográfico)

TERRÓN ALBARRÁN, Manuel, "Introducción", en Luis Zapata, Carlo Famoso, Ed. facs. de la edición príncipe de 1566, Institución Pedro de Valencia, Diputación Provincial de Badajoz,1981.

TERRÓN ALBARRÁN, Manuel, "Cristóbal de Mesa", en AA.VV., Historia de la Baja Extremadura, Real Academia de Extremadura de las Letras y las Artes, Badajoz, 1986, t. II, pp. 414-429 y 468-471.

TORTORETO, Alessandro, "Il Tasso in Spagna e in Portogallo", en Studi Tassiani, I, 1951, pp. 69-77.

VILÀ, Lara, "La épica española del Renacimiento (1540-1605). Propuestas para una revisión", en Boletín de la Real Academia Española, t.LXXXIII, 2003, pp. 137-150. 